\title{
Real-world effectiveness of valsartan on hypertension and total cardiovascular risk: review and implications of a translational research program
}

\author{
This article was published in the following Dove Press journal: \\ Vascular Health and Risk Management \\ 31 March 2011 \\ Number of times this article has been viewed
}

\author{
Ivo Abraham ${ }^{1,2}$ \\ Karen MacDonald ${ }^{2}$ \\ Christine Hermans ${ }^{3}$ \\ Ann Aerts ${ }^{3}$ \\ Christopher Lee 2,4 \\ Heidi Brié ${ }^{3}$ \\ Stefaan Vancayzeele ${ }^{3}$ \\ 'Center for Health Outcomes and \\ Pharmacoeconomic Research, and \\ Department of Pharmacy Practice \\ and Science, College of Pharmacy, \\ The University of Arizona, Tucson, AZ, \\ USA; ${ }^{2}$ Matrix 45, Earlysville, VA, USA; \\ ${ }^{3}$ Novartis Pharma, Vilvoorde, Belgium; \\ ${ }^{4}$ School of Nursing, Oregon Health \\ and Science University, Portland, \\ OR, USA
}

\begin{abstract}
The pharmacological efficacy of various monotherapy, single pill, and combination therapies of the angiotensin II receptor blocker valsartan have been established, mainly through randomized controlled trials that used similar methodological and statistical platforms and thus enabled synthesis of evidence. The real world effectiveness of valsartan has been studied extensively, but the relative lack of scientific and technical congruence of these studies render synthesis virtually impossible. To date, all have focused on blood pressure outcomes, despite evidence-based calls to grade antihypertensive treatment to patients' total cardiovascular risk. We review a $\mathrm{T} 3$ translational research program of seven studies involving valsartan monotherapy as well as single and separate pill combinations, and the determinants and effect on blood pressure and total cardiovascular risk outcomes. All seven studies examined not only the impact of valsartan-based regimens on blood pressure values and control, but also, within a statistical hierarchical approach, the physician- and patient-related determinants of these blood pressure outcomes. Two studies also investigated the determinants and outcomes of valsartan-based treatment on total cardiovascular risk - among the first studies to use this risk coefficient as an outcome rather than only a determinant. These seven studies included a total of 19,533 patients, contributed by 3434 physician-investigators in Belgium - a country particularly well-suited for observational effectiveness studies because of demographics and epidemiology. Each study used the same methodological and statistical platform. We summarize the impact of various valsartan regimens on such outcomes as blood pressure values and control, change in total cardiovascular risk, and reduction in risk by at least one category. We also review the results of statistical multilevel and logistic modeling of physician- and patient-related determinants on these outcomes, including the proportion of variance attributable to a physician class effect before patients enter the equation. In its different formulations, valsartan has major real-world benefits in lowering blood pressure and total cardiovascular risk within a 90-day period. It is essential to understand the physician- and patient-related determinants of blood pressure and total cardiovascular risk outcomes associated with valsartan treatment. Antihypertensive research should expand its historical focus on lowering blood pressure with an emphasis on lowering total cardiovascular research.
\end{abstract}

Keywords: valsartan, angiotensin II receptor blocker, hypertension, total cardiovascular risk, effectiveness, pharmaco-epidemiology

\section{Introduction}

Valsartan is an antihypertensive agent of the class of angiotension II receptor blockers (ARB). These agents block the angiotensin II type 1 ( $\mathrm{AT}_{1}$ ) receptor through
Correspondence: Ivo Abraham 620 Frays Ridge Road, Earlysville, VA 22936, USA

Tel +I 3039972987

Fax + I 9789458374

Email iabraham@matrix45.com 
all pathways, not just the renin-angiotensin-aldosterone pathway inhibited by angiotensin-converting enzyme (ACE) inhibitors. Blocking the $\mathrm{AT}_{1}$ receptor mediates the blood pressure (BP) elevating effects of angiotensin, including vasoconstriction, release of aldosterone and antidiuretic hormone, sympathetic activation, and constriction of the efferent glomerular arterioles. Further, by not blocking the angiotensin II type 2 ( $\left.\mathrm{AT}_{2}\right)$ receptor, the beneficial effects of stimulation of the $\mathrm{AT}_{2}$ receptor are maintained, including vasodilation, tissue repair, and cell growth inhibition. ${ }^{1}$

Several articles offer excellent reviews of randomized controlled trials (RCTs) on the efficacy of valsartan. ${ }^{2-5}$ The BP-lowering effect of valsartan has been documented across patient populations, including children, the elderly, women; patients at high risk for cardiovascular disease, with diabetes, and with chronic kidney disease; and across racial and ethnic groups. In addition to its antihypertensive effect, valsartan has also been shown to have a cardioprotective effect. $^{2}$ Treatment with valsartan reduces cardiovascular morbidity and mortality following myocardial infarct (MI), ${ }^{2}$ in patients with heart failure, ${ }^{2,3}$ and in patients with coronary artery disease, ${ }^{2}$ it also lowers the incidence of cerebrovascular accidents. ${ }^{2}$ Valsartan shares with other ARBs the ability to reduce circulating levels of high-sensitivity C-reactive protein and oxidized low-density lipoprotein, both biomarkers of endothelial dysfunction and cardiovascular risk. ${ }^{2}$ Valsartan has a renoprotective effect in patients with diabetes and/or chronic kidney disease as documented by reduced urinary albumin and protein excretion. ${ }^{2}$ Valsartan protects metabolic function in high risk hypertensive patients, including those with impaired glucose tolerance, diabetes, metabolic syndrome, and obesity. ${ }^{2}$ Moreover, valsartan is safe and well tolerated both in mono- and combination therapy and in a broad range of hypertensive patients. ${ }^{6}$

\section{Focus and rationale of review}

In this article, we build on the extensive literature on the efficacy of valsartan. We do so, neither by providing yet another review of efficacy results nor by trying to provide the first review of the even greater number of observational studies on the effectiveness of valsartan in routine clinical practice. An initial review of the body of observational studies shows great variability in the scope and the quality of objectives, methodology, analysis, and results $;^{7}$ the divergent findings are unlikely to be representative of valsartan's effectiveness in the daily clinical setting.

Instead, we have chosen to review a novel ' $\mathrm{T} 3$ ' translational (practice-based) research program ${ }^{8}$ on the effectiveness of valsartan in the real-world setting. This program involves seven studies, conducted since 2004 , on various formulations of valsartan on a total of 19,533 patients contributed by 7043 physician investigators in Belgium - a country particularly suited for observational effectiveness studies because of the logistical advantages of a small but densely populated country with two major cultures and languages, as well as urban and rural areas. Our research program employs an integrated framework for observational effectiveness issues in which the (conventional) question of whether valsartan works in routine clinical practice is complemented by several additional questions to gain a comprehensive understanding of the clinical dynamics of valsartan-based regimens in the management of hypertension.

Further, our research program was among the first in the health sciences to apply methodological and statistical techniques from the social sciences to investigate the extent to which the outcomes of treatment with valsartan are attributable to physician-related factors before any patient-related factors enter the equation. Patients seen by the same clinician are exposed to his/her hypertension knowledge, experience, and practice patterns. Technically, this violates the assumption of statistical independence of observations. Prior studies have not accounted statistically for the potential class effect of several patients being treated by the same physician-investigator, when in fact there is evidence of potential physician determinants. Therefore, both patient- and physician-related factors must be examined to better understand the variability in BP outcomes in daily clinical practice and any differences in RCT efficacy versus 'real-world' effectiveness.

A final novel feature of our research program, implemented in two recent studies, is the use of total cardiovascular risk (TCVR) as an outcome indicator of antihypertensive treatment with valsartan. The 2007 European Society of Cardiology-European Society of Hypertension (ESC-ESH) Guidelines and the 2009 ESH guideline reappraisal recommend that TCVR be assessed systematically in all patients with arterial hypertension and that the intensity of antihypertensive management be graded as a function of TCVR. ${ }^{9,10}$ This assessment can be done on the basis of the SCORE models that estimate patients' 10 -year risk of fatal CV disease for high and low risk European countries. ${ }^{11}$ Typically, studies use TCVR (or elements thereof) as a determinant or covariate of BP outcomes when, arguably, TCVR can be used as an outcome variable of the effectiveness of antihypertensive treatment. $^{12,13}$ 


\section{From efficacy to effectiveness}

Efficacy refers to how a treatment works in ideal circumstances, when provided to selected patients by providers most skilled at providing it. ${ }^{14}$ In contrast, effectiveness refers to how a treatment works under ordinary and variable conditions, prescribed by licensed clinicians with varying degrees of expertise and practicing across the spectrum of healthcare settings, to treat a heterogeneity of patients..$^{14,15}$

In order to secure the purest possible efficacy signal, randomized controlled trials tend to be selective in the patients recruited ('perfectly ill') and the investigators and centers participating in the trials (renowned and trusted for their scientific qualities). Treatment is defined narrowly by protocol and offers little latitude for deviation. Clinician-investigators are carefully trained in the identification and treatment of patients they enroll in the trial. Patients are monitored closely during treatment periods that tend to be short. Treatment is free to patients.

All this is both appropriate and essential for detecting an efficacy signal that demonstrates, as unambiguously as possible, the pharmacotherapeutic benefit of an agent under conditions of optimal control of potential (known and unknown) confounders. However, and certainly for treatments of chronic illnesses such as hypertension, RCT conditions are not representative of the clinical context in which these agents may be used after they have received marketing approval. In fact, RCTs for drug registration purposes bear poor resemblance to the real-world context of daily clinical practice. Patients are of different ages, with varying comorbidities, from across the socio-economic spectrum, and with compromising personal and family medical histories. They are unlikely to receive the guidance and monitoring given to subjects in RCTs. The cost of treatment is partially theirs. Clinicians, ranging from novice to expert, received their clinical training from institutions and facilities across the quality spectrum, and may have performed above or below the median of their education and training cohorts. Few facilities will match the scientific credentials of those used in the registration trials.

It is not surprising, then, that the real-world effectiveness of antihypertensive agents in reducing BP and achieving guideline-recommended targets ${ }^{16-18}$ may differ from the efficacy seen in RCTs. ${ }^{19}$ BP targets may not be reached, ${ }^{20-23}$ thus increasing patients' risk for target organ damage and cardiovascular and renal disease. ${ }^{20,24,25} \mathrm{BP}$ outcomes have been linked to patient-related factors, such as sociodemographics, heritability, history, comorbid conditions, lifestyle, knowledge about disease and treatment, and medication adherence. ${ }^{26,27}$ The observed variation in physicians' knowledge about antihypertensive therapy ${ }^{28,29}$ has not been linked directly to BP outcomes, though it is known that older physicians possess less factual knowledge and are less likely to adhere to the standards of care when treating hypertension..$^{30}$ There also is evidence of a relationship between physician practice patterns and BP outcomes. ${ }^{20,27,31,32}$

\section{Integrated framework for observational effectiveness studies}

RCTs are the indicated method for determining the efficacy of pharmacological agents. However, by necessity RCTs are constrained in terms of patients and clinicians included, and treatments must be limited to the agent under investigation so that unconfounded inferences about an agent's efficacy can be drawn. Observational studies are needed to examine the effectiveness of drugs previously documented to be efficacious. Most observational studies focus narrowly on evaluating a treatment's effectiveness under 'real-world' conditions, leaving key questions unanswered. The question of 'whether the treatment works?', while critical, does not address the equally important questions of 'when does the treatment work, and when not?', 'in whom does the treatment work, and in whom not?', 'why does the treatment work in some patients but not in others?', 'why does the treatment work with some clinicians but not with others?', and 'why is the treatment tolerated by some patients but not by others?'

We have developed an integrated framework for observational studies, which has become a de facto quality model to assure clinical relevance, scientific value, and technical merit. Figure 1 presents a flowchart of the framework used in our research program. Driven by a possible efficacyeffectiveness gap in ARB treatment - despite the availability of evidence-based practice guidelines for the management of hypertension - the framework includes four scientific goals operationalized into seven research steps.

The first goal is to determine the variability in BP values, BP control, and the residual TCVR after treatment with a valsartan-based regimen. Consequently, step 1 evaluates, on the basis of observed BP values, whether the hypertension has been alleviated and whether BP is now within control range. More recently, step 1 also evaluates the extent to which TCVR has been reduced as a function of lowered BP.

The second goal explores the determinants of observed blood pressure reduction at both the physician- and the patient-level. At the physician-level, we evaluate their knowledge of hypertension management, in particular as described in evidence-based practice guidelines. We examine the extent 


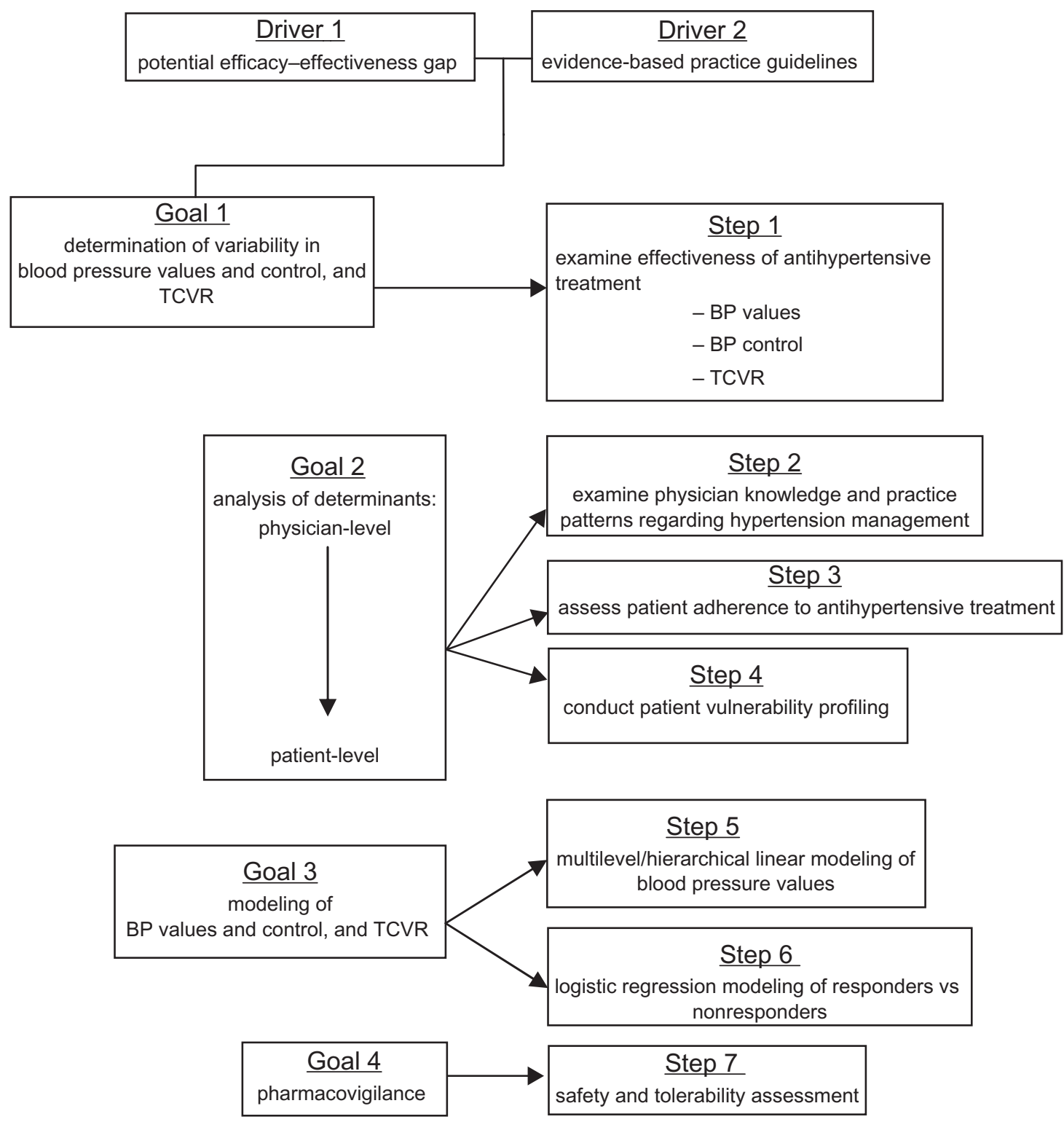

Figure I Integrated framework for observational effectiveness studies; the focus on total cardiovascular risk was added in 2007. Abbreviations: BP, blood pressure; TCVR, total cardiovascular risk.

to which they practice relative to these guidelines (step 2). We also collect demographic and professional data.

At the patient level, we assess whether patients adhered to their prescribed regimen (step 3). Instead of attempting to quantify adherence with 'pin-point' accuracy, we advocate the use of brief measures that can be integrated easily into routine clinical practice. These measures may not provide the 'true' level of a patient's adherence, but we do not believe this is necessary. Clinicians do not have the time for extensive adherence assessment. Short and easy methods that give them an impression as to whether treatment adherence is a problem in a given patient have been shown to be highly predictive of the risk for poor treatment response and uncontrolled BP. ${ }^{33}$
We also collect data related to demographics, clinical status, and knowledge.

Step 4 aims to develop a heuristic profile of patient vulnerability to poor treatment outcomes. Deterministic algorithms to determine cardiovascular outcomes are available (eg, SCORE, ${ }^{11}$ Framingham ${ }^{34}$ ) but are seldom used in primary care. Reasons include the time requirements and the poor fit into the clinical flow of primary care encounters. Clinicians tend to view deterministic models as prescriptive and discounting their clinical expertise in evaluating patients and assessing risk. Similar to adherence assessment, clinicians prefer clinically intuitive guidance for identifying patients who may be less likely to achieve good treatment outcomes. ${ }^{35}$ 
The third goal is to model BP outcomes and changes in TCVR. This is done using hierarchical linear (step 5) and logistic regression methods (step 6). Hierarchical refers to statistical methods in which the class effect on outcomes is estimated before actual outcomes are calculated; in our research program, the effect of the class of physician as each of them contributed several patients to a study and the ensuing loss of independence of observation. In the process, the proportion of variance in BP outcomes associated attributable to the treating physician is estimated. In step 6 , logistic regression methods are applied to identify independent predictors of why some patients do not respond to antihypertensive treatment with valsartan.

The final goal concerns continued pharmaco-vigilance. Observational studies tend to have larger patient samples than RCTs. This adds statistical power to the ability to detect safety signals that may not have been detected in prior RCTs. Thus observational effectiveness, combined with other postapproval activities, offer a critical complement to RCTs to detect low-frequency adverse events with a statistically low likelihood of being detected in efficacy trials.

\section{Review of studies}

The research program comprises seven studies on various valsartan regimens conducted between 2004 and 2009: PREVIEW, ${ }^{19}$ IMPROVE, ${ }^{36}$ ADVANCE, ${ }^{37}$ INSIST, ${ }^{38}$ eNOVA, ${ }^{39}$ BSCORE $^{40}$ and EXCELLENT. ${ }^{41}$ Tables 1 and 2 summarize the studies in terms of year of initiation, evaluable samples, and key patient demographics (Table 1) and valsartan formulations included (Table 2). Studies were initiated between 2004 and 2008, with the last one (EXCELLENT) completed in 2009. Over the course of the program, all approved monotherapy and (single-pill) combination formulations were studied, with the exception of valsartan $320 \mathrm{mg}$. A total of 19,533 evaluable patients were contributed by 3434 physician investigators. Five studies included well over 3000 patients each. Mean $( \pm \mathrm{SD})$ age was consistent across studies, and the weighted average was 63.6 years. There were minor shifts in gender distribution across studies, but on average gender was equally distributed. On average, slightly less than a quarter of patients were diabetic.

\section{Core objectives}

Consistent with Figure 1, the core objectives across the seven studies were to:

1. Assess systolic (SBP) and diastolic (DBP) blood pressure and BP control at 90 days in patients receiving a valsartan regimen as second-line treatment because first-line treatment failed or was not tolerated;

2. Determine the percentage of variance in BP values at 90 days attributable to a physician class effect;

3. Examine the hierarchical (patients 'nested' under physicians) determinants of BP values at 90 days; and

4. Identify independent predictors of non-response to valsartan-centric treatment.

In addition, the BSCORE and EXCELLENT studies also aimed to:

1. Assess residual TCVR at 90 days, as well as the proportion of patients who achieved a reduction in TCVR of at least one category;

2. Determine the percentage of variance in residual TCVR at 90 days attributable to a physician class effect;

3. Examine the hierarchical determinants of residual TCVR at 90 days; and

4. Identify independent predictors of achieving an improvement in TCVR of at least one category.

\section{Core methodology Design}

All studies included a baseline assessment at the time that treatment with valsartan was initiated, and a follow-up assessment approximately 90 days later. The decision to treat with

Table I Key characteristics of studies and samples

\begin{tabular}{|c|c|c|c|c|c|c|}
\hline \multirow[t]{2}{*}{ Study } & \multirow[t]{2}{*}{ Year initiated } & \multicolumn{2}{|c|}{ Evaluable samples } & \multicolumn{3}{|l|}{ Patients } \\
\hline & & Patients & Physicians & Age $(M \pm S D)$ & $\%$ male & $\%$ diabetic \\
\hline PREVIEW & 2004 & 3,194 & 504 & $63.4 \pm 11.9$ & 47.7 & 20.4 \\
\hline IMPROVE & 2004 & 3,950 & 684 & $63.2 \pm 12.3$ & 48.7 & 19.2 \\
\hline ADVANCE & 2005 & 3,599 & 602 & $63.6 \pm 12.0$ & 49.4 & 22.6 \\
\hline INSIST & 2006 & $\mathrm{I}, 0 \mathrm{|} 4$ & 308 & $63.6 \pm 12.0$ & 48.5 & 32.3 \\
\hline eNOVA & 2006 & 733 & 284 & $64.0 \pm 11.4$ & 49.0 & 40.2 \\
\hline BSCORE & 2008 & 3,497 & 354 & $63.8 \pm 12.0$ & 52.3 & 23.6 \\
\hline EXCELLENT & 2008 & 3,546 & 698 & $63.8 \pm 11.7$ & 53.9 & 27.0 \\
\hline \multirow[t]{2}{*}{ Weighted avg } & & & & $63.6 \pm 12.0$ & 50.3 & 23.7 \\
\hline & & 19,533 & 3,434 & & & \\
\hline
\end{tabular}


Table 2 Valsartan formulations included in studies

\begin{tabular}{|c|c|c|c|c|c|c|c|c|}
\hline & $80 \mathrm{mg}$ & $160 \mathrm{mg}$ & $\begin{array}{l}80 \mathrm{mg} / / 2.5 \mathrm{mg} \\
\text { HCTZ }\end{array}$ & $\begin{array}{l}160 \mathrm{mg} / 12.5 \mathrm{mg} \\
\text { HCTZ }\end{array}$ & $\begin{array}{l}160 \mathrm{mg} / 25 \mathrm{mg} \\
\text { HCTZ }\end{array}$ & $\begin{array}{l}5 \mathrm{mg} \\
\text { amlodipine/ } \\
80 \mathrm{mg}\end{array}$ & $\begin{array}{l}5 \mathrm{mg} \\
\text { amlodipine/ } \\
160 \mathrm{mg}\end{array}$ & $\begin{array}{l}10 \mathrm{mg} \\
\text { amlodipine/ } \\
160 \mathrm{mg}\end{array}$ \\
\hline PREVIEW & $\sqrt{ }$ & $\sqrt{ }$ & $\sqrt{ }$ & & & & & \\
\hline IMPROVE & $\sqrt{ }$ & $\sqrt{ }$ & $\sqrt{ }$ & $\sqrt{ }$ & $\sqrt{ }$ & & & \\
\hline ADVANCE & $\sqrt{ }$ & $\sqrt{ }$ & $\sqrt{ }$ & $\sqrt{ }$ & $\sqrt{ }$ & & & \\
\hline INSIST & & & & & $\sqrt{ }$ & & & \\
\hline eNOVA & $\sqrt{ }$ & $\sqrt{ }$ & $\sqrt{ }$ & $\sqrt{ }$ & & & & \\
\hline BSCORE & $\sqrt{ }$ & $\sqrt{ }$ & $\sqrt{ }$ & $\sqrt{ }$ & $\sqrt{ }$ & & & \\
\hline EXCELLENT & & & & & & $\sqrt{ }$ & $\sqrt{ }$ & $\sqrt{ }$ \\
\hline
\end{tabular}

Abbreviation: HCTZ, hydrochlorothiazide.

valsartan was made by the prescribing physician based on his/her best clinical judgment. Being an observational study, there were no required tests and all data collected were as available from routine clinical practice.

All studies complied with the Declaration of Helsinki. Approvals were obtained from appropriate ethical committees and conform to Belgian legislation and regulations and European Union directives regarding the use of human subjects. All subjects provided informed consent.

\section{Sampling}

Eligible for participation in any of the studies were male and female patients whose treating physician decided independently and per best clinical judgment to prescribe valsartan as second-line mono- or polytherapy, including single-pill combinations with hydrochlorothiazide (HCTZ) or amlodipine (Table 2). Patients had to be hypertensive, defined as DBP $\geq 90 \mathrm{mmHg}$ ( $\geq 80 \mathrm{mmHg}$ for diabetic patients) and/ or SBP $\geq 140 \mathrm{mmHg}$ ( $\geq 130 \mathrm{mmHg}$ for diabetic patients). Patients with controlled SBP and/or DBP at baseline were eligible if the conversion to a valsartan regimen occurred because prior-line treatment was not tolerated. Patients with sensitivities to any ARBs, thiazides, or calcium channel blockers were excluded; as were patients on any investigational drug in the 30 days before enrolment, and patients prescribed other ARBs during the study period.

\section{Variables and measurements}

The studies included only patient data collected routinely in clinical practice. The core data model was developed on the basis of literature review and clinical experience. Though there were occasional minor variations across the seven studies in terms of data elements included, essentially all studies collected conceptually and/or operationally the same data. All data models are available from the corresponding author.

\section{Core data model}

Physician questionnaire: practice type, location/setting, patient mix; demographics; sources of information and knowledge related to hypertension; self-reported hypertension management practices; prescription patterns; management of side effects; SBP/DBP thresholds for treatment initiation and intensification; perceptions of patient adherence; and knowledge of practice guidelines.

Patient baseline data: demographics; anthropometrics; hypertension and CV history; comorbidities; lifestyle; prior antihypertensive medications; SBP and DBP; physician-reported TCVR (BSCORE and EXCELLENT studies only); clinical status; starting doses; all concomitant anti-hypertensive and other relevant medications (prescribed as per physicians' clinical judgment); selfreported and physician-rated (0-100) visual analog scale adherence within the past 4 weeks; and adherence and non-adherence behaviors.

Patient follow-up data (90 days): SBP and DBP; residual physician-reported TCVR (BSCORE and EXCELLENT studies only); clinical status; changes in dosing since previous visit; concomitant medication(s) taken or changed since previous visit (prescribed as per physicians' clinical judgment); selfreported and physician-rated adherence within the past 4 weeks ( $0-100$ visual analog scale with higher values indicating better adherence); and adherence and non-adherence behaviors.

Blood pressure: $\mathrm{BP}$ was measured three times at 1- to 2-minute intervals, in a sitting position after 5 minutes of rest. The mean was recorded as the mean sitting systolic (MSSBP; hereafter SBP) and diastolic blood pressure (MSDBP; hereafter DBP). BP control was defined per the 2007 ESH-ESC guidelines prevailing at the time of the study: $\mathrm{SBP}<140 \mathrm{mmHg}$ and/or DB $<90 \mathrm{mmHg}$, except for patients with diabetes mellitus and/or high or very high TCVR, in which case targets were $<130 / 80 \mathrm{mmHg}$. ${ }^{9}$ 
The recent 2009 reappraisal $^{10}$ advocates $<140 / 90 \mathrm{mmHg}$ targets for all populations, including diabetics, but as the studies were conducted under the ESH-ESC 2007 guidelines, we used the lower BP targets for diabetic patients or patients with high or very high $\mathrm{CV}$ risk in the analysis.

TCVR (BSCORE and EXCELLENT): TCVR was reported by physicians using the SCORE cross-classification of BP by risk factors (eg, smoking, dyslipidemia), metabolic syndrome, diabetes, and established CV disease (MI, coronary artery disease, heart failure, cerebrovascular conditions, peripheral arterial disease) or renal disease (defined as serum creatinine $>1.5 \mathrm{mg} / \mathrm{dL}) .{ }^{42}$ Possible classifications included: average risk - low added risk - moderate added risk - high added risk - very high added risk. We computed 'change in TCVR' by subtracting baseline TCVR from follow-up TCVR, yielding possible scores from -4 (greatest improvement in TCVR) to +4 (greatest worsening of TCVR). We also classified patients dichotomously as showing or not showing a reduction in TCVR by at least one category at 90 days. Patients with established CV or renal disease or patients at baseline in the average risk category were not included in these latter two calculations as they could not improve in the TCVR classification.

\section{Specialized statistical analyses}

In addition to general summary statistics, each study included advanced modeling techniques to identify determinants of BP values, TCVR change scores, BP control, and achieving a TCVR reduction of at least one category.

\section{Multilevel or hierarchical linear modeling}

Each participating physician recruited several patients, therefore patients could not be considered independent but instead 'nested' under their treating physician. We assumed that the $n_{j}$ patients recruited by the $j t h$ physician might share some proportion of variance in BP values and TCVR change attributable to their common physician, possibly affecting both variables prior to any patient-specific variables. We applied unconditional and conditional two-level hierarchical linear modeling. ${ }^{43,44}$ Unconditional modeling quantified the variability in patient outcomes attributable to a physician class effect (intraclass correlation coefficient [ICC]). In the conditional models BP and TCVR were first examined in light of physician-level variables. The coefficients thus derived were used subsequently in the estimation of patient determinants of the BP and TCVR effectiveness outcomes.

\section{Hierarchical logistic regression ${ }^{45}$}

This was used to model patient- and physician-level determinants of uncontrolled BP at 90 days; and, in the BSCORE and EXCELLENT studies, to identify independent predictors of improvement in TCVR.

We have presented summary statistics from random effects meta-analyses ( $Z$ statistic, Hedges g, $P$ value) to estimate effects of BP reduction, taking into account between and within study differences, and correlation between pre- and post BP values. We have included match-paired statistics (McNemar's and Liddell's tests) to present the statistical significance of changes in BP control compared with baseline. We have presented McNemar-Bowker's test to help quantify the improvements in TCVR (improvement in matched distributions). With respect to ICCs, we present statistics from random effects meta-analyses across studies ( $Z$ statistic, $P$ value) for SBP and DBP, and $\chi^{2}$ for each study with TCVR (test against the null ICC of 0.00 ).

\section{Results}

In this section, we review the aggregate findings across the various studies for the effectiveness outcomes: BP values and control (Table 3); as well as TCVR for the BSCORE and EXCELLENT studies (Table 4); the proportion of variance in these effectiveness outcomes that is accounted for by a physician class effect (Table 5); the multilevel modeling of SBP (Table 6), DBP (Table 7), and TCVR (Table 8); logistic modeling of uncontrolled SBP (Table 9), DBP (Table 10), combined SBP/DBP (Table 11); and achieving a reduction in TCVR of at least one category (Table 12).

\section{Effectiveness outcomes}

\section{Blood pressure}

SBP and DBP values at baseline and after 90 days of valsartan-centric treatment were similar across the seven studies (Table 3). Using weighted averages, SBP decreased from a mean $( \pm \mathrm{SD})$ of $155.9 \pm 15.4 \mathrm{mmHg}$ to $137.5 \pm 11.8 \mathrm{mmHg}$, while DBP decreased from $91.5 \pm 9.6 \mathrm{mmHg}$ to $82.0 \pm 7.5$. On the aggregate, then, valsartan regimens were associated with absolute reductions in mean SBP of $-18.4 \mathrm{mmHg}$ $(Z=-27.573$; Hedges $g=1.225$, both $P<0.0001)$ and mean DBP of $-9.5 \mathrm{mmHg}(Z=-43.768$; Hedges $\mathrm{g}=1.173$, both $P<0.0001)$ compared with baseline values.

On average, $38.2 \%$ had controlled SBP, 58.2\% controlled DBP, and $32.0 \%$ controlled SBP and DBP combined at 90 days (Table 2). Although BP control rates varied across our studies, there were significant improvements 
Table 3 Blood pressure values and blood pressure control rates at baseline and 90 days

\begin{tabular}{|c|c|c|c|c|}
\hline \multirow[t]{3}{*}{ Systolic } & \multicolumn{2}{|c|}{$\begin{array}{l}\text { Blood pressure } \\
(\mathrm{mmHg})\end{array}$} & \multicolumn{2}{|c|}{$\begin{array}{l}\text { Controlled blood } \\
\text { pressure }\end{array}$} \\
\hline & Baseline & 90 days & Baseline & 90 days \\
\hline & $\mathbf{M} \pm \mathbf{S D}$ & $\mathbf{M} \pm \mathbf{S D}$ & $\%$ & $\%$ \\
\hline PREVIEW & $154.4 \pm 15.5$ & $139.0 \pm 12.0$ & 9.0 & 38.6 \\
\hline IMPROVE & $157.0 \pm 16.1$ & $138.7 \pm 12.3$ & 6.6 & 40.4 \\
\hline ADVANCE & $155.7 \pm 15.3$ & $137.8 \pm \mid 1.3$ & 6.6 & 42.3 \\
\hline INSIST & $158.5 \pm 17.2$ & $139.3 \pm 13.7$ & 5.6 & 34.9 \\
\hline eNOVA & $156.6 \pm 14.3$ & $138.0 \pm 11.3$ & 4.5 & 38.9 \\
\hline BSCORE & $154.7 \pm 15.3$ & $135.3 \pm 11.5$ & 4.6 & 36.9 \\
\hline EXCELLENT & $156.3 \pm 14.6$ & $136.2 \pm 11.3$ & 2.7 & 33.3 \\
\hline $\begin{array}{l}\text { Weighted } \\
\text { average }\end{array}$ & $155.9 \pm 15.4$ & $137.5 \pm 1 \mid .8$ & 5.8 & 38.2 \\
\hline \multicolumn{5}{|l|}{ Diastolic } \\
\hline PREVIEW & $91.3 \pm 9.2$ & $82.6 \pm 7.4$ & 25.5 & 65.5 \\
\hline IMPROVE & $91.6 \pm 9.6$ & $81.9 \pm 7.5$ & 23.5 & 66.9 \\
\hline ADVANCE & $91.9 \pm 9.5$ & $82.6 \pm 7.4$ & 23.0 & 64.3 \\
\hline INSIST & $93.1 \pm 10.3$ & $82.5 \pm 8.1$ & 18.8 & 55.8 \\
\hline eNOVA & $93.0 \pm 9.2$ & $82.7 \pm 7.4$ & 15.8 & 59.9 \\
\hline BSCORE & $90.7 \pm 9.8$ & $80.7 \pm 7.7$ & 16.5 & 48.8 \\
\hline EXCELLENT & $91.4 \pm 9.7$ & $81.7 \pm 7.3$ & 13.3 & 45.3 \\
\hline $\begin{array}{l}\text { Weighted } \\
\text { average }\end{array}$ & $91.5 \pm 9.6$ & $82.0 \pm 7.5$ & 20.1 & 58.2 \\
\hline \multicolumn{5}{|c|}{ Combined systolic and diastolic } \\
\hline PREVIEW & & & 7.3 & 34.4 \\
\hline IMPROVE & & & 4.8 & 34.9 \\
\hline ADVANCE & & & 5.0 & 36.1 \\
\hline INSIST & & & 4.0 & 30.8 \\
\hline eNOVA & & & 3.1 & 33.3 \\
\hline BSCORE & & & 3.0 & 28.7 \\
\hline EXCELLENT & & & 1.7 & 25.5 \\
\hline Weighted & & & 4.3 & 32.0 \\
\hline average & & & & \\
\hline
\end{tabular}

in proportions of patients with controlled BP compared with baseline levels of control (all matched-paired $P<0.001)$.

\section{TCVR}

On average, across the BSCORE and EXCELLENT studies, patients' TCVR classification decreased by $-0.74 \pm 0.95$ category over 90 days of antihypertensive treatment (Table 4).
At 90 days, about $60 \%$ of patients had a residual TCVR that was at least 1 category lower than at baseline. More telling, perhaps, are the observed shifts in risk categories from baseline to follow-up. As shown in Figure 2, whereas at baseline $45.9 \%$ of patients were classified as having high added risk or very high added risk, this proportion declined to $25.6 \%$ just 90 days later. Compared with baseline, improvements in TCVR were significant in both BSCORE and EXCELLENT (both McNemar-Bowker $\chi^{2}>1000 ; P<0.0001$ ). The modal subcohort of $42.0 \%$ with moderate added risk at baseline was reduced to $26.6 \%$ at follow-up, when low added risk became the modal subcohort (34.4\%). At 90 days, almost half of patients $(47.7 \%)$ qualified for the average risk and low added risk categories.

\section{Attribution of variance to physician class effect}

On average across the seven valsartan studies, $22 \%$ of the variance in $\operatorname{SBP}(Z=22.954 ; P<0.0001)$ and $24 \%$ of the variance in $\operatorname{DBP}(Z=22.619 ; P<0.0001)$ at 90 days was attributable to a physician class effect. The average variance in residual TCVR accounted for by a physician class effect was $15 \%$ (BSCORE $\chi^{2}=87.48 ; P<0.0001$ : EXCELLENT $\left.\chi^{2}=79.20 ; P<0.0001\right)$. Thus, anywhere from about one fifth to one quarter of patients' BP values after 90 days of valsartan-centric treatment were determined by the treating physician - and this before any patient variables entered the equation. Similarly, about one seventh of patients' change in cardiovascular risk was a function of the treating physician.

\section{Multilevel modeling of blood pressure values and TCVR}

Tables 6 through 8 summarize the results of the multilevel modeling of SBP, DBP, and change in TCVR after 90 days of treatment with valsartan-centric antihypertensive regimens in each of the seven studies. Following the observed model intercept, the top panel lists patient- and the bottom panel physician-related variables that were retained.

Table 4 Mean change in total cardiovascular risk (TCVR) and percentage of patients with reduction in TCVR $\geq 1$ category from baseline to 90 days

\begin{tabular}{|c|c|c|c|c|}
\hline & \multicolumn{3}{|c|}{ Total cardiovascular risk } & \multirow{2}{*}{$\begin{array}{l}\text { Percent of patients with TCVR } \\
\text { reduction } \geq \text { I risk category }\end{array}$} \\
\hline & $\begin{array}{l}\text { Min } \\
\text { ( } \downarrow \text { TCVR) }\end{array}$ & $\begin{array}{l}\text { Max } \\
(\uparrow \text { TCVR) }\end{array}$ & $\mathbf{M} \pm \mathbf{S D}$ & \\
\hline BSCORE & -4 & +3 & $-0.75 \pm 0.94$ & 60.9 \\
\hline EXCELLENT & -4 & +3 & $-0.73 \pm 0.96$ & 58.2 \\
\hline Weighted average & & & $-0.74 \pm 0.95$ & 59.5 \\
\hline
\end{tabular}

Notes: Negative indicates decline in TCVR, positive indicates increase in TCVR. 
Table 5 Percent of variance in effectiveness outcomes at 90 days attributable to a physician class effect

\begin{tabular}{llll}
\hline & \multicolumn{3}{l}{ Blood pressure } \\
\cline { 2 - 4 } & Systolic & Diastolic & TCVR \\
\cline { 2 - 4 } & $\%$ & $\%$ & $\%$ \\
\hline PREVIEW & 24 & 25 & \\
IMPROVE & 21 & 24 & \\
ADVANCE & 22 & 22 & \\
INSIST & 24 & 23 & \\
eNOVA & 24 & 18 & 13 \\
BSCORE & 21 & 26 & 16 \\
EXCELLENT & 22 & 26 & 15 \\
Weighted average & 22 & 24 & \\
\hline
\end{tabular}

Abbreviation: TCVR, total cardiovascular risk.

\section{Systolic blood pressure}

Across the seven studies (Table 6), patient-related determinants of elevated SBP (positive slope coefficient) included: age; SBP at the initial diagnosis of a patient's hypertension and SBP at start of a valsartan-centric treatment regimen; risk factors such as diabetes and retinopathy (as a proxy of advanced diabetes), total cholesterol at baseline, and being a patient who fits the profile of being highly vulnerable to uncontrolled blood pressure. ${ }^{35}$ Patients' medication behavior was a consistent determinant. Nonadherence had a SBP-elevating effect. In contrast, patient and/or physician rated adherence had a SBP-lowering effect. Physicians who had been practicing longer tended to have patients with higher SBP levels at the end of 90 days. Conversely, seeing more hypertensive patients was associated with a decrease in SBP; as was using evidence-based systolic triggers for initiation or intensification of antihypertensive treatment.

\section{Diastolic blood pressure}

Patient-related variables that had a DBP-elevating effect included being male; DBP at initial diagnosis and at initiation of valsartan treatment; obesity; fitting the profile of high vulnerability to uncontrolled hypertension; and longer time intervals between blood pressure measurements (Table 7). Nonadherence had a negative effect on DBP, but adherence a positive effect. Other DBP-lowering variables included age, concomitant ACE inhibitor treatment. As with SBP, patients seeing older physicians tended to have higher DBP, but physician experience in treating hypertension had a DBP-lowering effect. Using diastolic triggers for treatment initiation or intensification, and routinely calculating patients' overall cardiovascular risk were also predictive of lower DBP.

\section{TCVR}

The interpretation of slope coefficients for the multilevel models for changes in TCVR is the opposite of what applied to SBP and DBP. The intent was to measure improvement (and thus a decrease) in TCVR, with the best possible score being -4 and the worst score being +4 . Hence a positive slope coefficient indicates that a given variable worsens TCVR, whereas a negative coefficient denotes that a variable lessens and thus improves the patient's risk. TCVR worsened the higher the SBP at initial diagnosis and at initiation of valsartan treatment, and if the patient had diabetes or dyslipidemia (Table 8). In contrast, being female and not having pre-existing risk factors was associated with improvements in TCVR. The largest effects were observed for patients' TCVR level at baseline; note the successive, consistently increasing negative coefficients for each level of added risk relative to the average risk for the population at large. Except for two apparent paradoxical physician-related variables, no physician determinants were retained.

Logistic modeling of determinants of uncontrolled blood pressure and achieving a TCVR reduction of at least one category.

\section{SBP control}

The likelihood of uncontrolled SBP (Table 9) is a function of such patient factors as age, SBP at the initial diagnosis of hypertension and at baseline, diabetes, fitting the high vulnerability profile, being at high added or very high added TCVR, smoking, hypercholesterolemia, non-adherence, and months elapsed since last BP measurement. Conversely, uncontrolled SBP was less likely if the patient was male, had controlled SBP at baseline (and thus was started on valsartan because prior line of treatment was not tolerated), no pre-existing conditions or risk factors, and physician-rated adherence. On the physician end, while years in practice was associated with uncontrolled SBP, control was more likely if the physician knew the correct BP targets for non-diabetic patients and practices according to the recommended SBP thresholds for treatment initiation and intensification.

\section{DBP control}

Uncontrolled DBP was a function of the diastolic reading when hypertension was diagnosed, being diabetic or obese, fitting the high-vulnerability profile, and being at moderate added, high added, or very high added TCVR at start of valsartan therapy, and treatment non-adherence (Table 10). Increasing age, the absence of pre-existing conditions and risk factors, concomitant ACE inhibitor treatment, and physician-rated adherence 


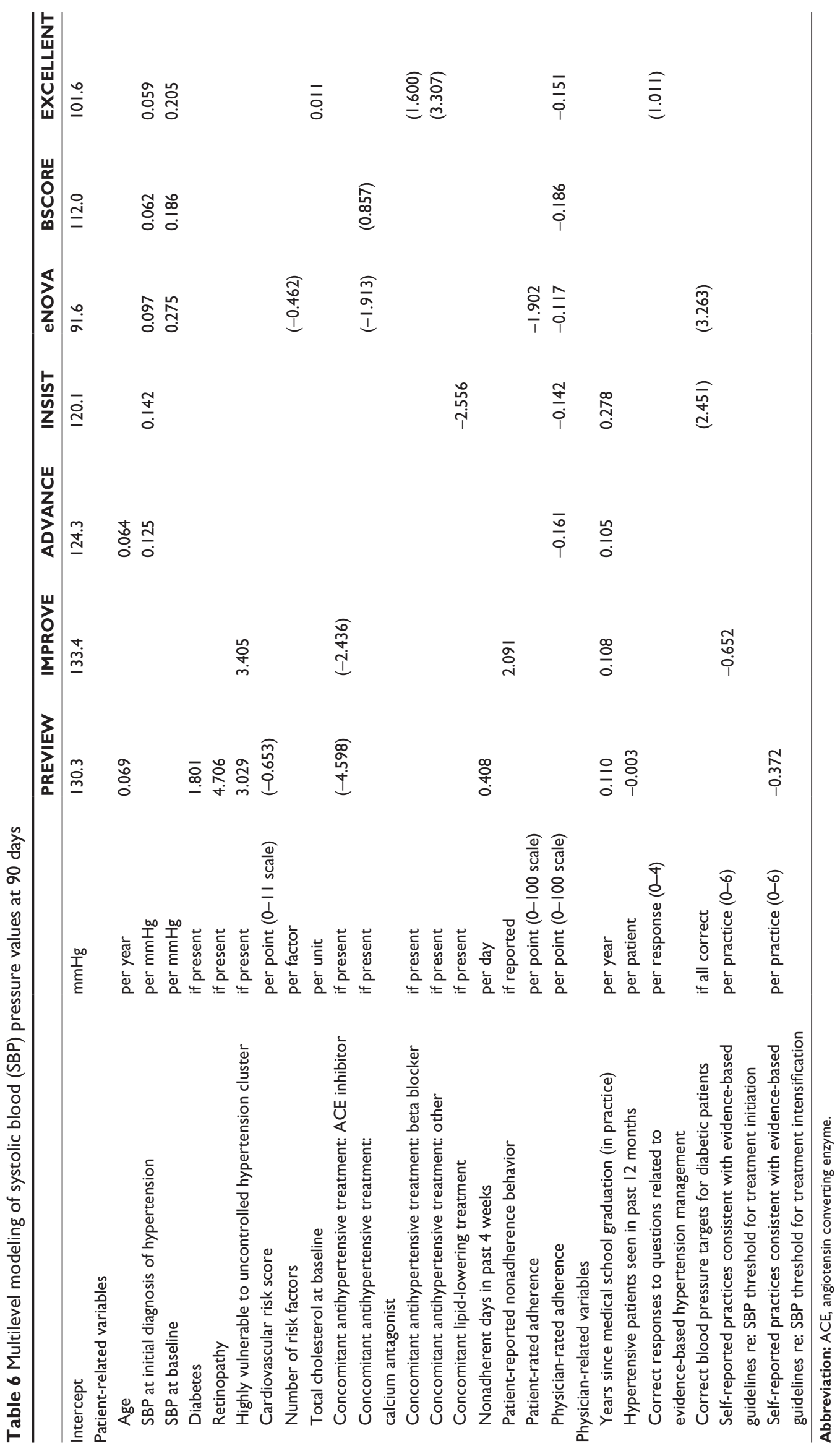




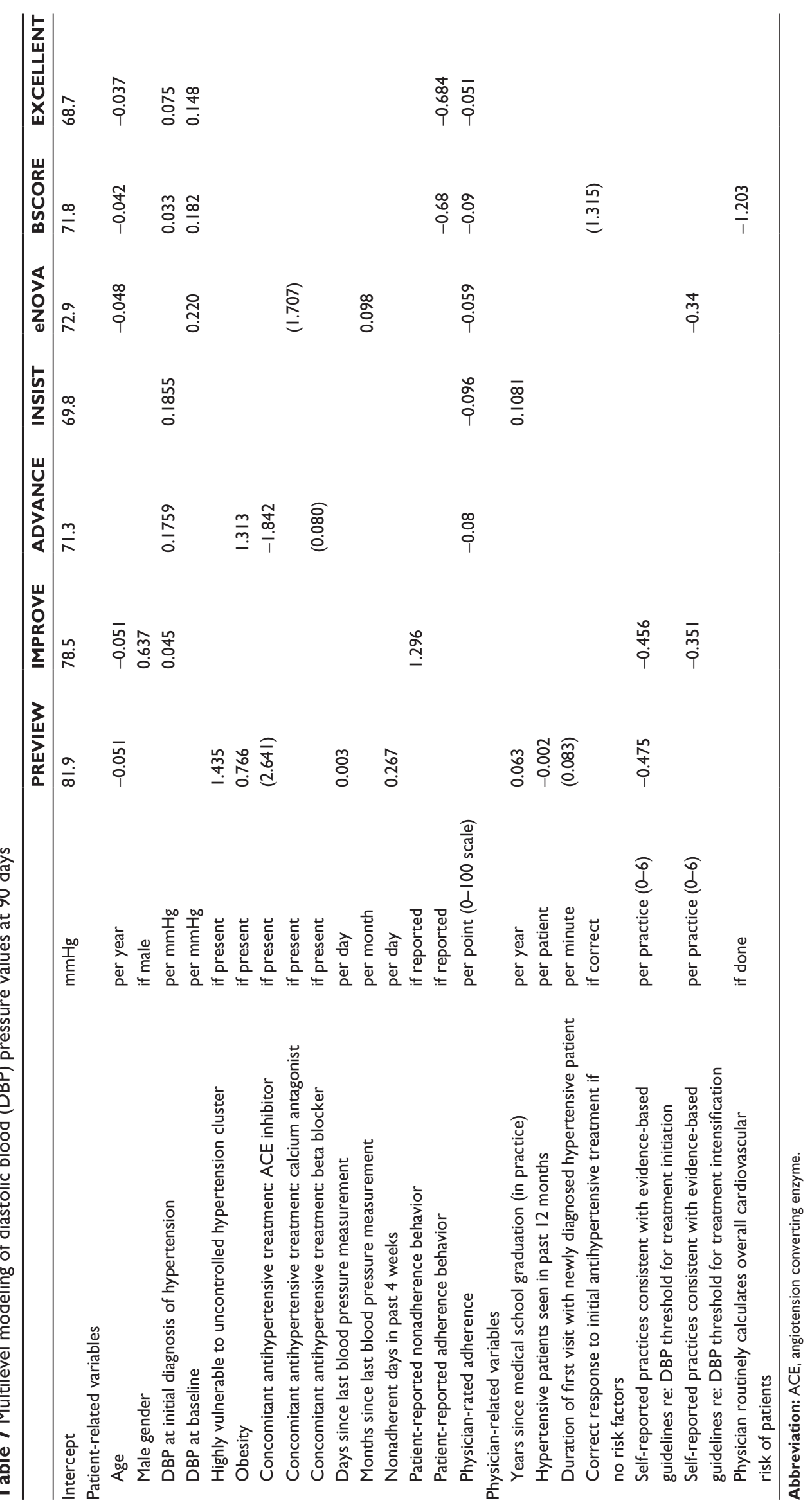


Table 8 Multilevel modeling of change in TCVR score from baseline to 90 days

\begin{tabular}{|c|c|c|c|}
\hline & & BSCORE & EXCELLENT \\
\hline Intercept & -4 to +4 & 0.982 & 1.222 \\
\hline \multicolumn{4}{|l|}{ Patient-related variables } \\
\hline SBP at initial diagnosis of hypertension & per $\mathrm{mmHg}$ & 0.004 & \\
\hline SBP at baseline & per $\mathrm{mmHg}$ & & 0.003 \\
\hline Female gender & if female & & -0.127 \\
\hline Total cardiovascular risk: low added risk & if present & -0.932 & $-1.14 \mid$ \\
\hline Total cardiovascular risk: moderate added risk & if present & -1.644 & -1.819 \\
\hline Total cardiovascular risk: high added risk & if present & -2.215 & -2.327 \\
\hline Total cardiovascular risk: very high added risk & if present & -3.263 & -3.414 \\
\hline Conditions and risk factors: no pre-existing & if present & -0.395 & -0.358 \\
\hline Conditions and risk factors: diabetes & if present & 0.750 & 0.626 \\
\hline Conditions and risk factors: dyslipidemia & if present & 0.193 & 0.117 \\
\hline Concomitant antihypertensive treatment: ACE inhibitor & if present & & 0.216 \\
\hline Concomitant antihypertensive treatment: diuretic & if present & & 0.109 \\
\hline Physician-rated adherence & per point (0-100 scale) & -0.009 & -0.009 \\
\hline \multicolumn{4}{|l|}{ Physician-related variables } \\
\hline $\begin{array}{l}\text { Correct response to initial antihypertensive treatment if } \\
\text { I or } 2 \text { risk factors present }\end{array}$ & if correct & 0.148 & \\
\hline $\begin{array}{l}\text { Correct blood pressure values for hypertension diagnosis } \\
\text { in diabetic patients }\end{array}$ & if all correct & & 0.116 \\
\hline
\end{tabular}

Abbreviations: ACE, angiotensin converting enzyme; TCVR, total cardiovascular risk; SBP, systolic blood pressure.

were predictive of controlled DBP. Whether a patient began valsartan treatment with controlled or uncontrolled DBP was associated with corresponding control status 90 days later. While, again, physicians' years in practice was predictive of uncontrolled DBP, a high volume of hypertensive patients over the 12 months preceding the study, increased frequency of visits in the first 3 months following the diagnosis of hypertension, and practicing in accordance with evidence-based DBP thresholds for treatment initiation and intensification were predictors of controlled DBP at 90 days.

\section{Combined SBP/DBP control}

Several of the determinants of uncontrolled SBP or DBP also influenced the likelihood of both SBP and DBP being uncontrolled (Table 11). On the patient end, negative determinants included: age, SBP at hypertension diagnosis and at baseline, diabetes, fitting the high-vulnerability profile, high added or very high added TCVR, prior MI, hypercholesterolemia, and non-adherence behavior. Positive determinants consisted of: male gender, no pre-existing conditions or risk factors, and physician-rated adherence; in addition to SBP and DBP both under control at baseline. Physician-wise, years in practice was associated with uncontrolled SBP/ DBP, while having seen more hypertension patients over the past 12 months, knowing the BP targets for non-diabetic patients, and practicing in accordance with SBP thresholds for treatment initiation and intensification made control of both SBP and DBP at follow-up more likely.

\section{TCVR reduction by at least one category}

Patients were more likely to reduce their TCVR by at least one category if at baseline they were in the moderate added, high added, or very high added TCVR categories, had no preexisting conditions, and were perceived by their physician as being adherent (Table 12). Alternately, being older, male, diabetic, and dyslipidemic made it less likely for patients to reduce their TCVR by at least one category. Understandably, the few patients who had both SBP and DBP controlled at baseline were also less likely to reduce their TCVR.

\section{Discussion}

Our studies confirm that second- or later-line treatment with valsartan, in its different formulations, has major pharmacotherapeutic benefits in lowering BP and TCVR within a 90-day time period in patients for whom prior line treatment failed or was not tolerated. These effects were observed with remarkable reliability across all seven studies - and thus across time, formulations, and heterogeneous populations of patients, physicians, and settings. Thus our program of research, with its conceptual, methodological, and statistical consistency, establishes the real-world effectiveness of valsartan-centric treatment regimens. Further, this pharmacotherapeutic benefit was shown to be complemented by modifying, managing, or taking into account patient- and physician-level variables that may have a negative impact on BP and TCVR outcomes; and optimizing those that may enhance these outcomes. In other words, we can conclude 


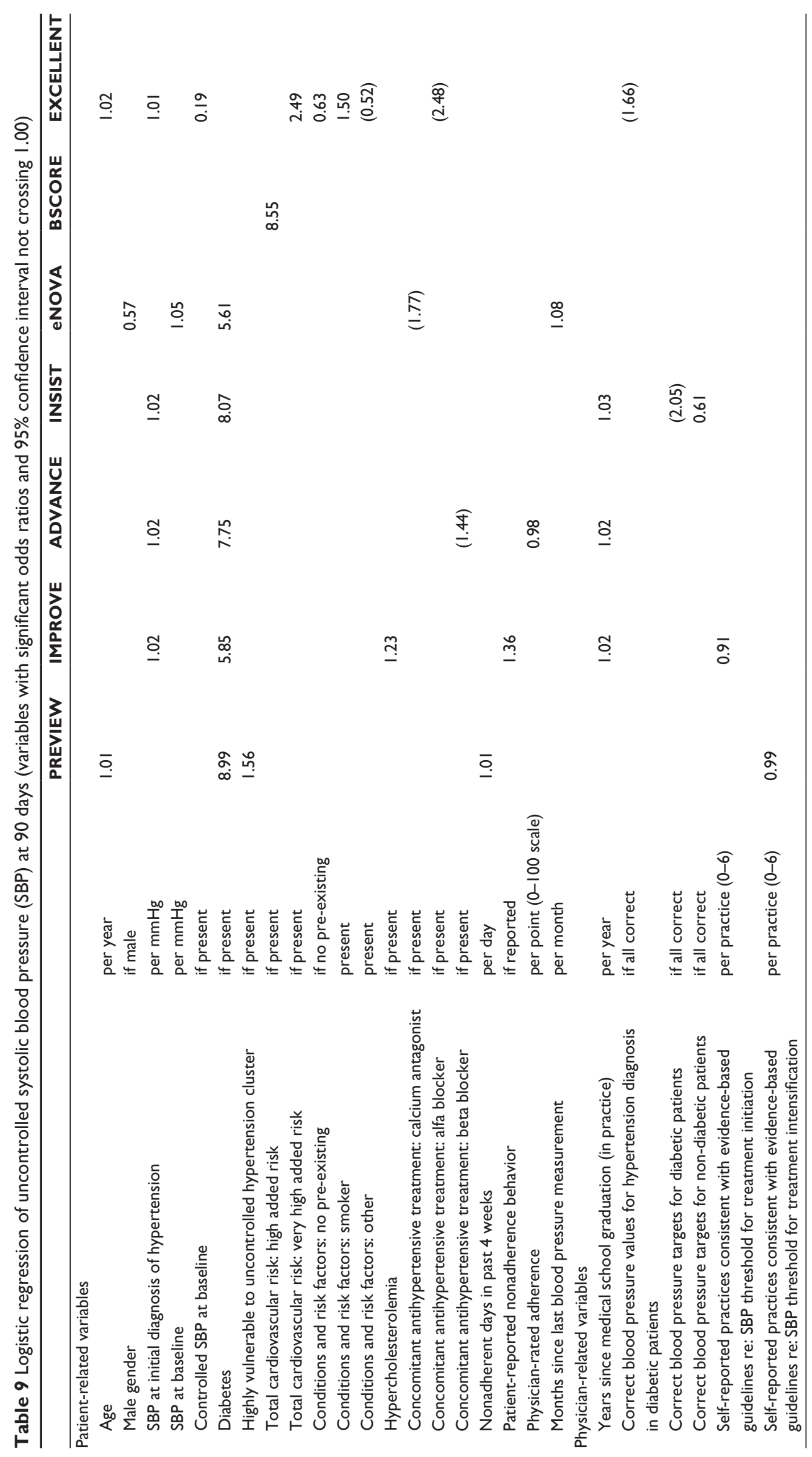




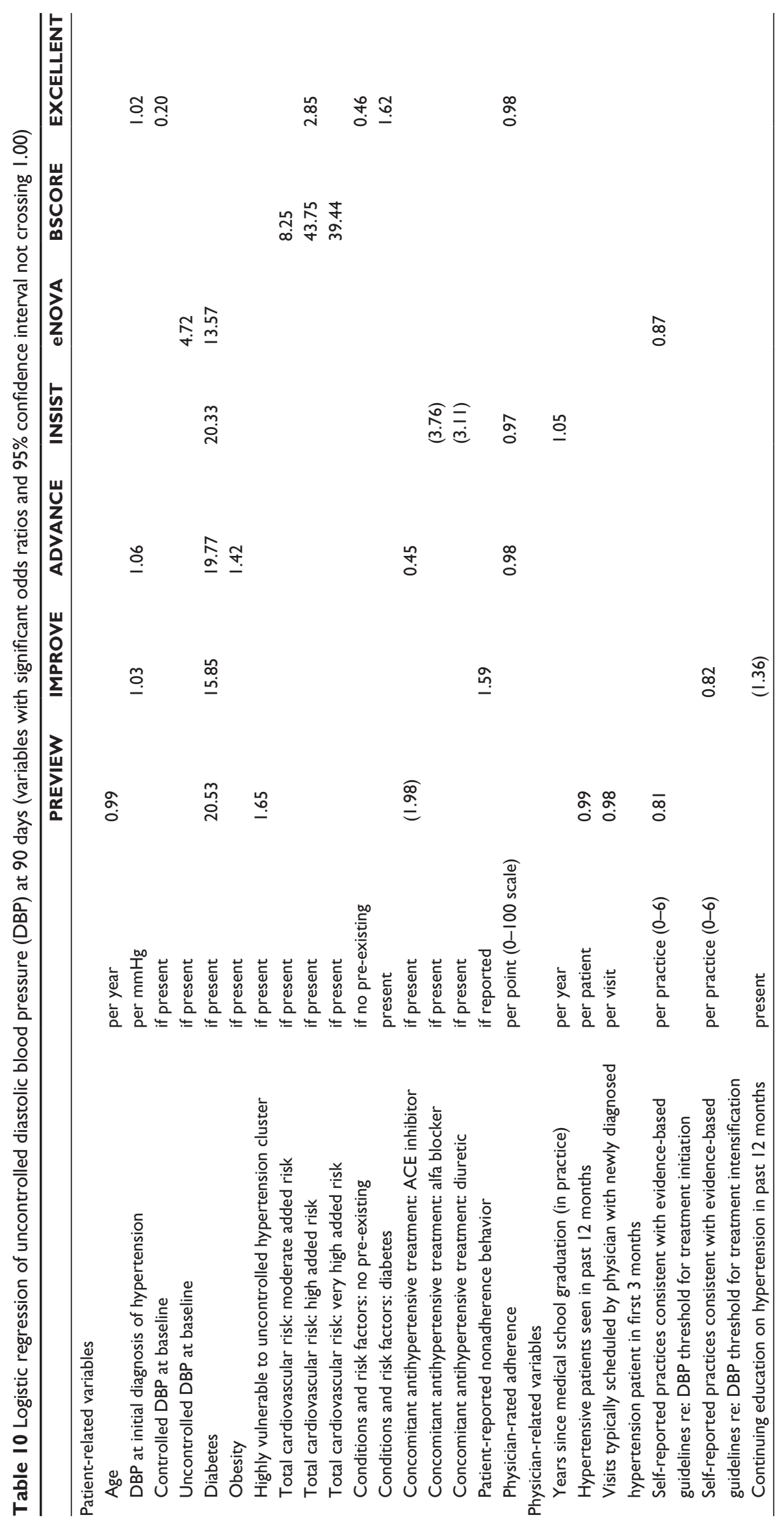




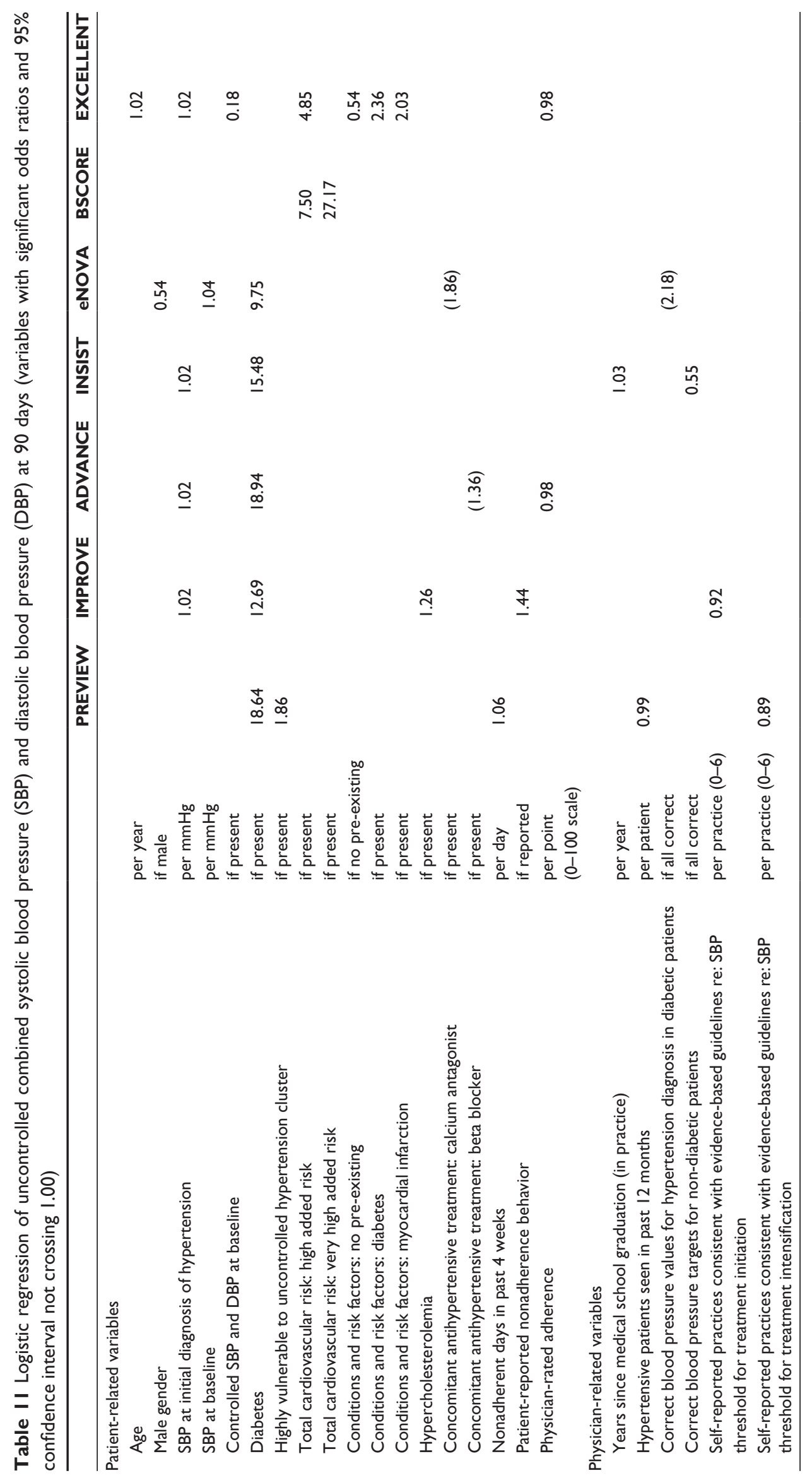


Table 12 Logistic regression of achieving a TCVR reduction (improvement) $\geq$ I category from baseline to 90 days (variables with significant odds ratios and $95 \%$ confidence interval not crossing 1.00 )

\begin{tabular}{|c|c|c|c|}
\hline & & BSCORE & EXCELLENT \\
\hline \multicolumn{4}{|l|}{ Patient-related variables } \\
\hline Age & per year & & 0.98 \\
\hline Male gender & if male & & 0.52 \\
\hline Controlled SBP and DBP at baseline & if present & 0.50 & \\
\hline Total cardiovascular risk: moderate added risk & if present & 5.57 & 3.02 \\
\hline Total cardiovascular risk: high added risk & if present & 11.12 & 3.19 \\
\hline Total cardiovascular risk: very high added risk & if present & 104.28 & 48.44 \\
\hline Conditions and risk factors: no pre-existing & if no pre-existing & 2.07 & 3.66 \\
\hline Conditions and risk factors: diabetes & if present & 0.19 & \\
\hline Conditions and risk factors: dyslipidemia & if present & 0.71 & \\
\hline Concomitant antihypertensive treatment: alfa blocker & if present & $(0.5 \mathrm{I})$ & \\
\hline Concomitant antihypertensive treatment: other than alfa blocker & if present & $(2.28)$ & \\
\hline Physician-rated adherence & per point (0-100 scale) & 1.03 & 1.02 \\
\hline \multicolumn{4}{|l|}{ Physician-related variables } \\
\hline $\begin{array}{l}\text { Correct responses to questions related to evidence-based } \\
\text { hypertension management }\end{array}$ & per response $(0-4)$ & & $(0.78)$ \\
\hline
\end{tabular}

Abbreviations: DBP, diastolic blood pressure; SBP, systolic blood pressure; TCVR, total cardiovascular risk.

deductively that valsartan is indeed efficacious in the real world as its pharmacologic benefits were shown to prevail despite the large heterogeneity in patients, clinicians, and treatment approaches compared to RCTs.

We observed that valsartan regimens were associated with absolute reductions in mean SBP of $-18.4 \mathrm{mmHg}$ and mean DBP of $-9.5 \mathrm{mmHg}$ compared with baseline values. In their meta-analysis of 354 randomized trials of BP-lowering drugs, Law et $\mathrm{a}^{46}$ reported BP reductions associated with ARB treatments at the lowest available dose (eg, valsartan $80 \mathrm{mg}$ ), twice the lowest available dose (eg, $160 \mathrm{mg}$ ), and in dual combination therapy. For SBP these reductions were $-10.3 \mathrm{mmHg},-12.3 \mathrm{mmHg}$, and $-14.6 \mathrm{mmHg}$ respectively, well below the weighted average of $-18.4 \mathrm{mmHg}$ in our

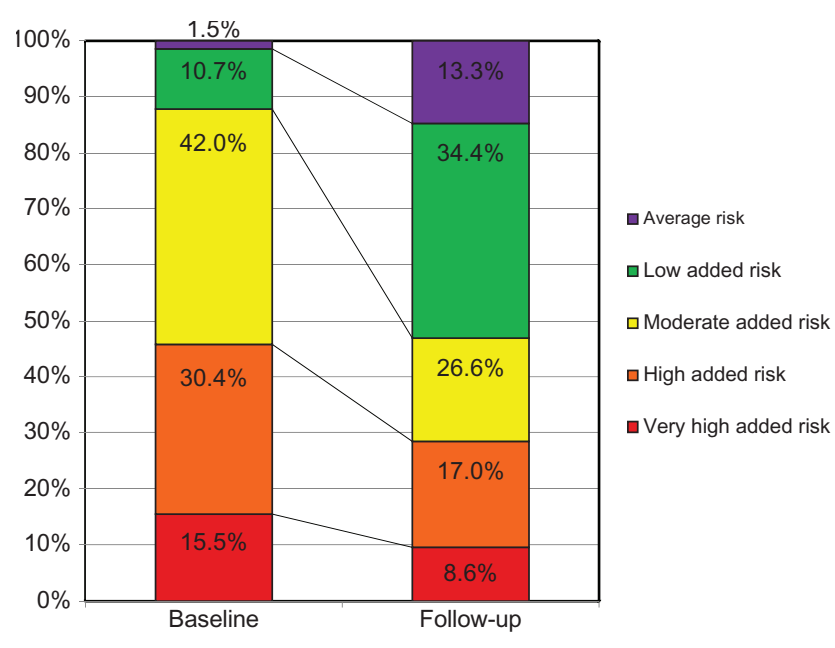

Figure 2 Shifts in total cardiovascular risk from baseline to follow-up. studies. Triple combination therapy was associated with a reduction of $-19.9 \mathrm{mmHg}$, slightly better than the single and dual therapies in our studies. Likewise, in this meta-analysis DBP reductions associated with the lowest available dose, twice the lowest available dose, and dual combination therapy were $-5.7 \mathrm{mmHg},-6.5 \mathrm{mmHg}$, and $-7.3 \mathrm{mmHg}$, respectively, compared with the weighted average of $-9.5 \mathrm{mmHg}$ in our studies. Again, triple therapy was slightly more effective $(-10.7 \mathrm{mmHg})$.

BP control rates varied across our studies, with later studies trending towards lower control rates. This trend can be explained quite readily as a function of the regimens studied. Over time, our studies involved increasingly stronger formulations of single and combination therapies of various dosages of valsartan, beginning with $80 \mathrm{mg}, 160 \mathrm{mg}$, and $8 \mathrm{mg} / 12.5 \mathrm{mg} \mathrm{HCTZ}$ in the PREVIEW study to the full complements of valsartan plus HCTZ (BSCORE) or amlodipine (EXCELLENT). Plausibly, our studies evolved from 'typical' hypertensive patients requiring second-line treatment to increasingly more difficult-to-treat, if not treatment-resistant, patients as studies progressed over time.

The observed control rates are cause for concern for clinicians as they may indicate persistent therapeutic inertia in hypertension management: not intensifying treatment when evidence-based targets have not been reached. On the other hand, the control rates in our study are not unusual for Europe. Using the same parameters as our studies (140 mmHg/90 mmHg; $130 \mathrm{mmHg} / 80 \mathrm{mmHg}$ if diabetic), the worldwide i-SEARCH cohort study reported overall SBP, DBP, and combined SBP/DBP control rates of $25.2 \%$, 
$42.5 \%$, and $21.2 \%$, respectively. ${ }^{47}$ For Northern European countries, which included Belgium, Germany, Sweden, and Switzerland, these rates were $17.5 \%, 35.5 \%$, and $13.4 \%$. Note that other studies have suggested different geographical control rates (SBP/DBP combined) for periods concurrent with ours, including $50.1 \%$ in the $\mathrm{US}^{48}$ and $65.9 \%$ in Canada ${ }^{49}$ versus $27.1 \%$ in central and eastern Europe ${ }^{50}$ and $28.0 \%$ in England. ${ }^{51}$ This divergence may be a function of differences in awareness and treatment across regions, though study design differences may contribute just as much. As our studies employed convenience referred samples, the i-SEARCH study ${ }^{47}$ may be a better benchmark than a population-based study like NHANES in the US. ${ }^{48}$ Regardless, all control rates reviewed here are below the $75 \%$ hypertension control rate considered 'optimal'. 52

Reductions and shifts in TCVR observed in our studies were due to hypertension management only - possibly a criticism of any claims about the observed effects on TCVR. Arguably, there might instead be reason for clinical optimism, albeit initial: adequate hypertension management in itself results in significantly lower residual cardiovascular risk, a finding we also observed in a recent study on the direct renin inhibitor aliskiren. ${ }^{13}$ One can only speculate what the results would be of conjointly managing blood pressure, glucose, lipids, obesity, diet, activity, smoking, and alcohol consumption in patients at varying levels of TCVR. ${ }^{12}$ The average decreases in the incidence of stroke $(35 \%-40 \%)$, coronary events $(20 \%-25 \%)$, and congestive heart failure (50\%) associated with antihypertensive therapy ${ }^{16}$ therefore might rise if more than one element of the TCVR equation is addressed clinically.

TCVR underscores the importance of patient involvementfrom adherence to their prescribed medication regimens to making the necessary life style modifications. It has been hypothesized that providing patients with information on their global coronary risk may lead to subsequent declines in risk. A recent systematic review of 18 studies concluded that such information may increase a patient's accuracy of perceived risk and motivate those at moderate to high risk to start therapy. However, it was associated with only $-0.2 \%$ to $-2 \%$ 10-year reductions in Framingham scores, and whether this was a function of patient knowledge or the intensity of the accompanying interventions was unclear. ${ }^{53}$ If patient knowledge is indeed not power, ${ }^{54}$ the answer may lie in using this information to motivate patients into better self-care.

\section{Multilevel and logistic modeling}

Our studies were the first to quantify the physician class effect in antihypertensive treatment. The implications are significant. Mathematically, SBP could be improved by $22 \%$ and DBP by $24 \%$ if any physician influence were removed. While admittedly a theoretical exercise, the SBP weighted average mean reduction of $-18.4 \mathrm{mmHg}$ could be extended to $-23.6 \mathrm{mmHg}$, and the corresponding DBP reduction of $-9.5 \mathrm{mmHg}$ to $-12.5 \mathrm{mmHg}$. This begs the question as to what physician-related determinants need to be addressed to decrease the diversity among physicians. The multilevel modeling results from our studies provide important insights in the relationship between experience, knowledge, and evidence-based practice.

\section{Paradoxical results or proxies for clinical vigilance?}

As summarized in Table 13, some patient variables were associated with outcomes that seemed counterintuitive; for instance, presenting with more risk factors or being treated concomitantly with other antihypertensive agents. Similarly, physician variables such as greater knowledge about hypertension, its management in general and in specific patient subgroups, identifying correct BP targets, guideline-congruent practice, recent continuing education in hypertension, and longer visits with newly diagnosed patients were statistically significant indicators of treatment outcome. Seemingly paradoxical, these results all point at - hypothetically at least - the importance of physician attention and should be considered, we believe, proxies of clinical vigilance.

\section{Modifiable, manageable, and fixed determinants}

Table 14 presents a conceptual summary of the determinants of BP outcomes, BP control, TCVR change scores, and TCVR reduction by one or more categories. Any variable retained at least once in the models (Tables 9 through 12) are specified in terms of their influence on the effectiveness parameters of interest. Distinguishing between modifiable, manageable, and fixed determinants, we focus here on the clinical implications.

\section{Patient \\ Modifiable patient determinants}

A first key modifiable factor, presenting without pre-existing conditions or risk factors, does not concern changing but rather maintaining clinical status. This requires patient education and patient self-care: teaching the patient about predisposing conditions and risk factors, but even more importantly, enabling patients to prevent conditions or risks for hypertension and TCVR: medication adherence, a healthy 


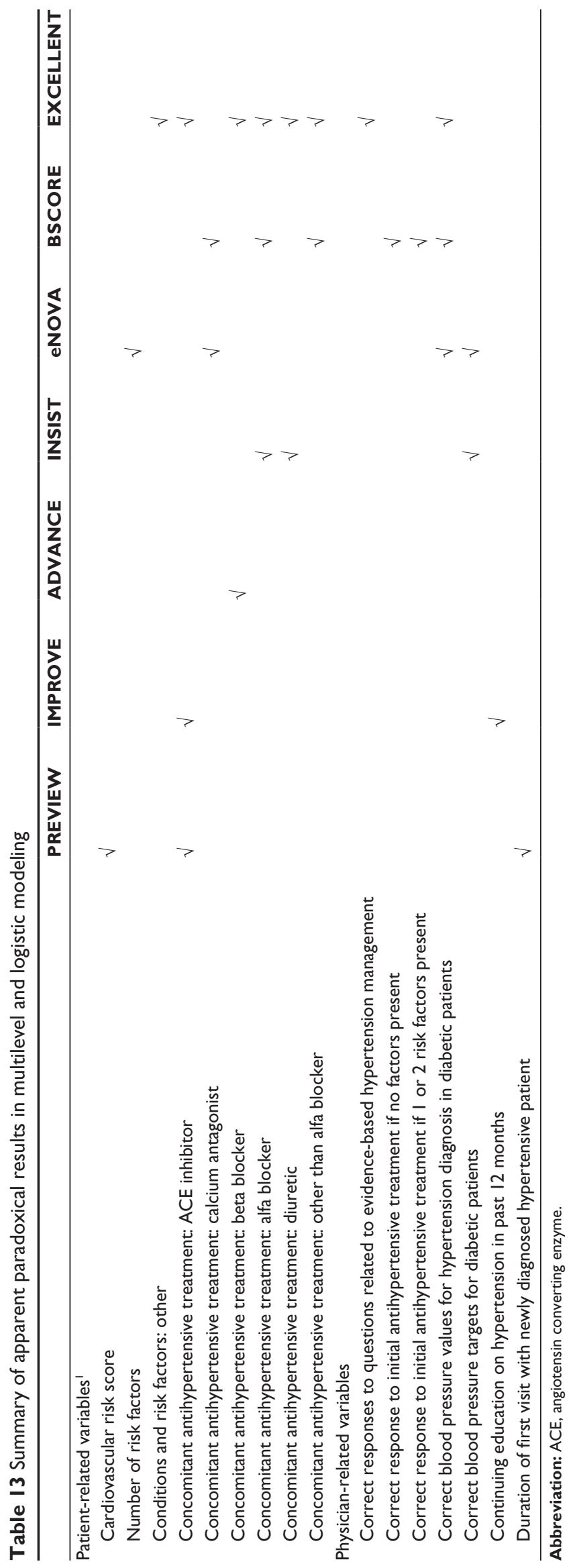

life style, regular monitoring of key markers and behaviors, to name the most important.

At the other end of the continuum are those patients where primary prevention failed and who fit the 'lazier, later, and unluckier' profile of being highly vulnerable to uncontrolled hypertension following treatment with a valsartan regimen (at least per the PREVIEW study). 19,35 This profile has not yet been shown to directly impact TCVR outcomes. It can be assumed to do so as it is an independent predictor of BP control ${ }^{35}$ and thus may have an effect on TCVR as a BP-linked indicator. These findings reaffirm the importance of patient self-care behavior, in particular treatment adherence and lifestyle modifications. As to the latter, our studies confirm that patients should not smoke; eat a low fat, carbohydrate balanced, and low sodium diet; lose weight; and implicitly (under the calculation of TCVR status) exercise condition- and age-appropriately. These lifestyle modifications will also benefit patients with dyslipidemia who, moreover, should be treated with lipid-lowering agents. Lifestyle-related (as opposed to metabolic) obesity is a modifiable variable as well.

Patients in our studies were in at least the second line of antihypertensive treatment, mainly because of failure of prior line treatment to achieve BP control. Many fell in the difficult-to-treat if not treatment-resistant categories. As BP control most often requires combination therapy, our modeling results indicate that concomitant ACE inhibitor therapy is effective, and certainly is indicated in patients with diabetes (for whom this is considered the standard of care). Note that all other classes of antihypertensive agents (prior to direct renin inhibitors) also emerged in the models - though in a paradoxical direction as a proxy of clinician vigilance. This underscores the importance of adjunct anti-hypertensive therapy to complement valsartan treatment.

TCVR is an eminently modifiable determinant. As the BSCORE $^{40}$ and EXCELLENT ${ }^{41}$ studies showed for valsartan, but also more recently the DRIVER ${ }^{13}$ study for aliskiren, TCVR can be reduced significantly through antihypertensive treatment. This breaks the vicious circle of hypertension and elevated TCVR, and adds preventive cardiovascular as well as renoprotective effects. The TCVR findings also reveal a direct relationship between severity of TCVR and the likelihood of achieving a reduction in TCVR following valsartan (or aliskiren) treatment: the more room there is for improvement, the greater the likelihood - logically so.

A final modifiable factor that may enhance valsartan treatment outcomes concerns BP monitoring. Shorter time intervals between clinic BP readings were associated with 


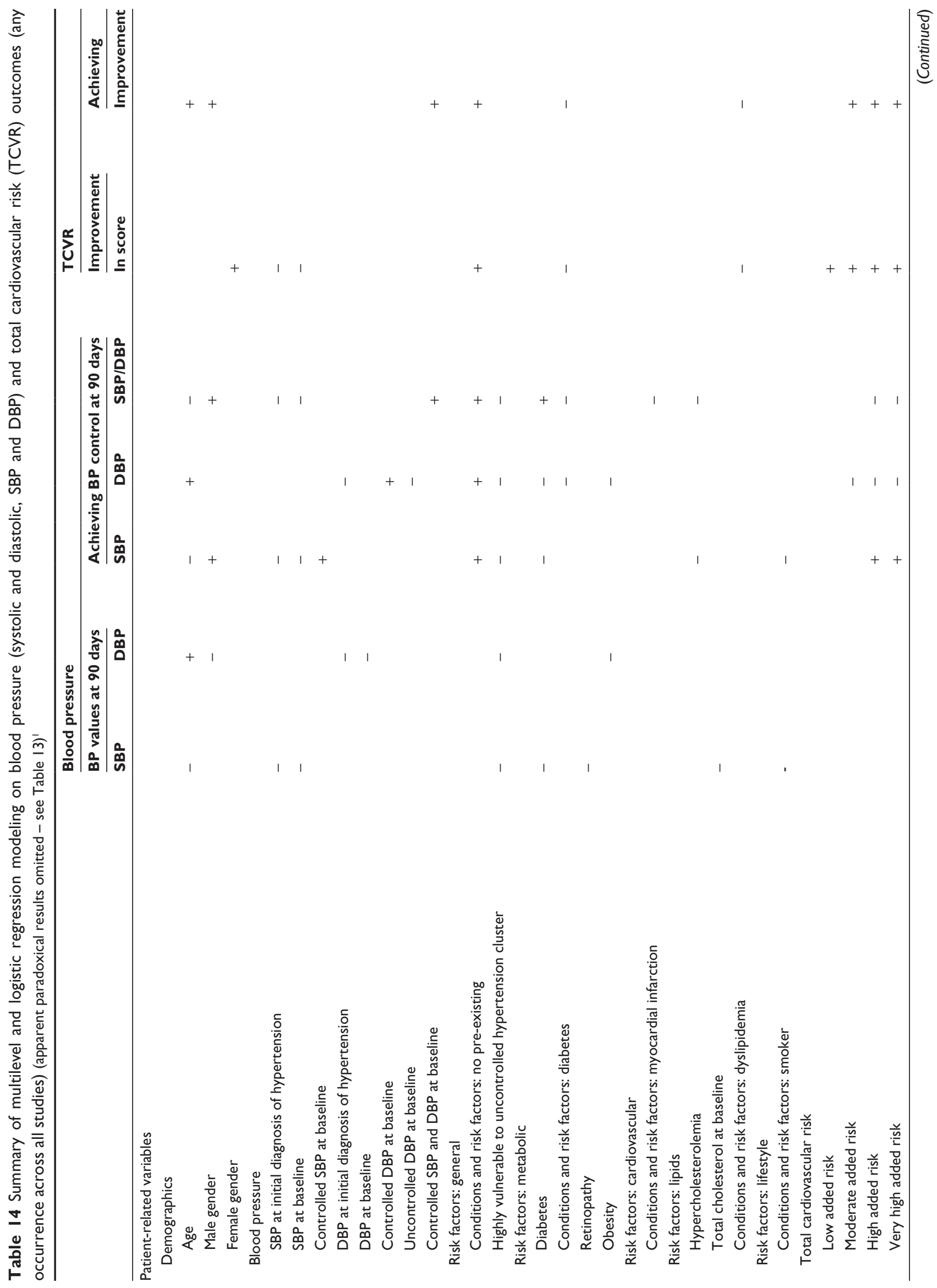




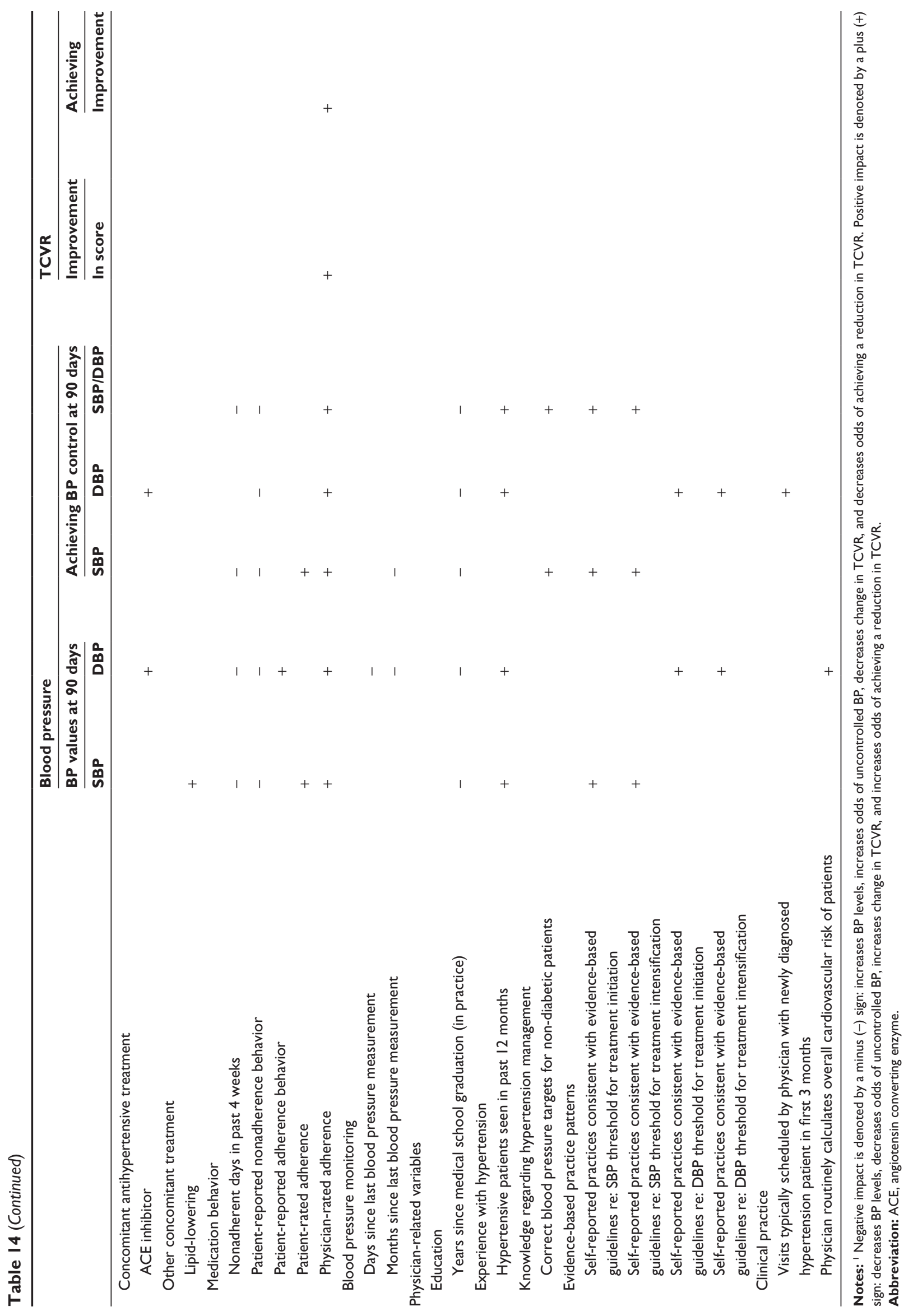


better treatment outcomes, most likely because this enables clinicians to intensify treatment sooner - reducing therapeutic inertia along the way. Patients may further benefit if they also perform home BP monitoring. A recent meta-analysis concluded that, compared with office monitoring alone, home monitoring added small but significant reductions in SBP and DBP, led to more frequent antihypertensive medication reductions, and was associated with less therapeutic inertia. $^{55}$

\section{Manageable patient determinants}

SBP and DBP levels at the initial diagnosis of hypertension, as well as SBP and DBP levels at the start of valsartan therapy, were associated with better BP and TCVR outcomes, which underscores the importance of early diagnosis and early intervention. The sooner high blood pressure is diagnosed (or, perhaps better, when patients move from normotensive or pre-hypertensive into grade I hypertension), the more likely it is that SBP and DBP will decrease, SBP and DBP will be controlled, TCVR will improve, and a TCVR reduction of at least one category will be achieved over 90 days of valsartan treatment.

Early diagnosis and early initiation of valsartan treatment had a singular effect on SBP reduction and SBP control, suggesting the effectiveness of valsartan in lowering isolated systolic hypertension. There was also an association of DBP at diagnosis and valsartan start with subsequent DBP reduction and control. This may reflect in part the historical practice of focusing on DBP in hypertension diagnosis and management.

$\mathrm{BP}$ reduction and control are more difficult to achieve in diabetic patients. This challenge was found in our studies as well (data not reported but available from the corresponding author), especially in patients with advanced diabetes (as evidenced, for instance, by retinopathy). Further, patients with diabetes fall by definition into a higher TCVR category and reductions in TCVR may be more difficult to achieve. Hence diabetes needs to be managed aggressively to improve BP outcomes and TCVR, to prevent (hypertension-compounded) chronic kidney disease, to manage the hypertensiondiabetes-dyslipidemia-renal disease axis, and to optimize the outcomes of antihypertensive treatment in general and with valsartan in particular.

Patients with a prior MI are less likely to achieve BP control, in addition to having an increased TCVR a priori. To promote general cardiovascular health, prevent an MI recurrence, and reduce MI-associated cardiovascular morbidity, hypertension control is essential. As valsartan is among the most potent antihypertensive agents, it should be among the treatments of choice for patients with a history of MI.

\section{Fixed patient determinants}

Our studies confirm prior evidence that advanced age negatively affects SBP, but positively affects DBP when considered separately (compromises achieving combined SBP/DBP control). Advanced age increases the likelihood of reducing TCVR by at least one catgeory. ${ }^{23,48,56-59}$ In a subanalysis of patients age 65 and older in the PREVIEW study, control rates were lower yet modeling identified factors similar to those in the study at large. ${ }^{60}$ Importantly, the percentages of variation in BP values attributable to a physician class effect were higher: $27 \%$ for SBP (versus 24\% in PREVIEW and 22\% in this present analysis) and $32 \%$ for DBP (versus $27 \%$ and $24 \%$, respectively). This underscores the importance of physicians treating older adults within the guidelines for this subpopulation.

Further, for each increase in age by 10 years, the likelihood of controlled BP decreases by $10 \%$ for men and $20 \%$ for women. ${ }^{61}$ Across our studies, men were more likely to achieve SBP and SBP/DBP control, as well as TCVR reduction by one or more categories; whereas women showed greater improvements in TCVR score. In another subanalysis of PREVIEW, fewer women than men reached SBP and SBP/ DBP control. The multilevel and logistic models showed that men who lacked regular exercise or were non-adherent, were more vulnerable to uncontrolled SBP, whereas women were more vulnerable to uncontrolled BP because of identifiable physician-level variables such as the number of hypertensive patients seen in the past 12 months and the number of follow-up visits to achieve BP control. ${ }^{62}$

Understandably, controlled BP at baseline, when valsartan treatment was initiated, was predictive of BP control at 90 days. Each study enrolled small proportions of patients with controlled BP who did not tolerate their prior antihypertensive treatment. It can be assumed that these patients tended to have less severe hypertension and/or be good responders and/or be good adherers. Yet the importance of this finding is that BP control can be sustained successfully with valsartan treatment.

\section{Physician Modifiable physician determinants}

Our studies revealed several physician-related variables that are modifiable through both medical education and selfinitiated physician change. Knowledge about evidence-based hypertension management is critical. Knowing BP targets for patients in general, and specific subgroups such diabetic, 
elderly, or high risk patients, is associated with better treatment outcomes. Limited knowledge impairs physicians' ability to treat more complex patients such as the difficultto-treat or the treatment-resistant. On the other hand, one cannot expect general practitioners to be able to manage all patients and to be 'pseudo hypertension specialists'. Hence the need for regular interaction with specialists, and timely referral of poorly responding or highly complex patients to these specialists for consultation.

While clinical knowledge does not assure clinical behavior change, our studies consistently point at the importance of practicing in accordance with evidence-based guidelines for treatment initiation and intensification, ie, knowing when and how to start and when and how to escalate antihypertensive treatment (in this case, with valsartan). This will avoid delayed pharmacological intervention, and reduce therapeutic inertia when patient response is below target. In the process, regular monitoring of patients especially in the first 3 months after diagnosis and treatment initiation, and routinely calculating patients' total cardiovascular risk, is associated with better patient outcomes. Assuming our proxy hypothesis is plausible, diagnostic and therapeutic physician vigilance is critical in preventing adverse treatment outcomes.

Our studies identified a relationship between (selfreported) guideline-congruent practice and BP outcomes. Important in itself, this finding does not answer the more critical question of whether individualized, evidence-based care at the individual patient level translates into lower and controlled BP. Evidence-based medicine may be forgetting to focus on evidence-based individualized patient care decisionmaking. ${ }^{63}$ However, a quantification of the extent to which the care of each individual patient increases the likelihood of treatment response has been shown to increase the likelihood of positive treatment outcomes by a factor of almost 3 in the management of chemotherapy-induced anemia in cancer patients. ${ }^{64}$ Future studies in hypertension should benefit from a similar assessment.

\section{Manageable and fixed physician determinants}

Physician experience may be a double-edged sword in hypertension management in primary care. The number of hypertensive patients in the twelve months preceding start of a study was associated with better BP values and better control rates after 90 days of valsartan treatment. Logically, experience by volume should indeed translate into better outcomes, perhaps in part because clinicians' treatment patterns become more consistent across patients. Yet by being generalists, primary care physicians cannot be expected to 'subspecialize' in particular diseases at the expense of their public trust function to serve patients in their communities. What could be expected realistically is that they regularly appraise their confidence in, and the outcomes of, antihypertensive treatment in their patients - and be provided with support to do so. One indeed learns from (safe) selfexperimentation and self-observation. It is not uncommon for clinicians to engage in exercises in which they (often unsystematically) observe their practice behavior and try to infer treatment effectiveness from (most often unsystematically collected) data. They should be supported to 'micro-trial' to garner 'micro-evidence', and thus gain clinical confidence and change clinical practice behavior. ${ }^{65}$

In contrast to the positive effect of experience by patient volume stands the negative association of experience in years with BP outcomes. The longer the time since physicians had graduated from medical school and had been in practice, the greater the likelihood of poorer BP outcomes. One cannot assume this to be a linear relationship. This would mean that patients treated by junior physicians would have the best outcomes - an argument that can be negated without the need for scientific evidence. Rather, the relationship might be concave, where physicians' treatment outcomes improve in the early career years, peak over some period of time, only to decline later on. ${ }^{30}$

\section{Real-world effectiveness of valsartan}

Valsartan's real-world effectiveness was demonstrated consistently across the continuum of treatment response, with particularly encouraging results in difficult-to-treat if not treatment-resistant patients. The latter is important as, until the approval of aliskiren, valsartan quadruple lowest available dose $(320 \mathrm{mg})$ as well as lowest available dose $(80 \mathrm{mg})$ and double lowest available dose $(160 \mathrm{mg})$ singlepill combinations with HCTZ $25 \mathrm{mg}$ or with $5 \mathrm{mg}$ or $10 \mathrm{mg}$ amlodipine (Table 2) were the most potent antihypertensive agents available. Blood pressure control remains a moving target; there is more uncontrolled disease despite improved therapy, ${ }^{16}$ and aliskiren and aliskiren/HCTZ have become the antihypertensive treatment of (the proverbial) last resort. This means that valsartan-based regimens should be the prevailing if not standard model to manage patients ranging from those with (modest) hypertension not controlled by prior line therapy to those persistently failing to respond to escalating combination therapies and intensifying dosing schemes.

Critically, and despite its pharmacological benefits, valsartan's real-world effectiveness is amplified significantly through parallel preventive and interventive actions. 
These should involve patients in general but especially target those with elevated risk for non-response or secondary cardiovascular, renal, or other organ or physiological damage. Just as critically, this should occur within a context of enabling physicians to gain in knowledge and experience and to practice in accordance with evidence-based guidelines. Lastly, while we did not report such data from our studies in this article, the positive safety and tolerance profile of valsartan should be considered in clinical decision-making as well.

More generally, using valsartan as the exemplar, our findings confirm and extend an earlier proposed three-step approach to optimizing the real-world effectiveness of antihypertensive treatment. ${ }^{19}$ First, clinicians should identify patients less likely to achieve BP control. Deterministic models may ensure the greatest accuracy, however heuristic, clinically more intuitive, yet empirically validated methods may prove easiest to use in routine primary care practice. ${ }^{35}$ Within the (time) confines of a clinical encounter, it may be better to get a sense of risk and empathetically communicate this concern to the patient. This might indeed be more effective than calculating the actual percentage of increased risk for an adverse cardiovascular event and citing that statistic to the patient during a clinical encounter. Most likely, the patient will have difficulty placing this statistic within a fair probabilistic context. ${ }^{66}$

Nonetheless, to support their own clinical decision-making, clinicians should routinely assess patients' TCVR and, per guidelines, ${ }^{9,10}$ grade antihypertensive therapy accordingly. In the absence of heuristic methods, deterministic models are indicated. While they may take more time, the pay-off for anyone with added cardiovascular risk is warranted from clinical, quality of life, and cost perspectives. Second, at the risk of repetition, clinicians and patients should focus on modifiable and manageable patient- and physician-related determinants known to affect BP values and TCVR scores positively or negatively (while being cognizant of the fixed). Lastly, the goal should be to lower the odds of uncontrolled $\mathrm{BP}$ and the odds of not achieving reductions in TCVR.

\section{Patient adherence}

Patients indeed have a significant self-care responsibility in the management of their hypertension and the prevention of target organ damage and major cardiovascular events. A meta-analysis documented that the likelihood of a poor or null response to antihypertensive treatment is reduced by $30 \%$ but that the odds of responding to treatment are 3.44 if patients are adherent. ${ }^{67}$ Osterberg and Blaschke ${ }^{68}$ summarize strategies to improve medication adherence in general and these strategies apply to hypertension as well: identifying the potential for or patterns of non-adherence; focusing on the patient by eliciting feelings, listening, reinforcing desirable behaviors, and customizing treatment to patient wishes; patient education through explanation and clear instructions; engaging the patient's family, social, and community environment; encouraging the use of medicationtaking systems; and altering treatment to more 'forgiving' medications. In hypertension, the large number of studies about non-adherence is by far not matched by (non) controlled studies on effective interventions. Hence, general suggestions ${ }^{67}$ are helpful but largely untested suggestions that are unlikely to reduce the persistent problem of patient non-adherence.

One new insight from our research program is that intuitive physician assessment may have a positive effect certainly on BP and TCVR outcomes. Physician-rated adherence using a visual analog scale was predictive of lower SBP and DBP; SBP, DBP, and SBP/DBP control; change in TCVR; and achieving a TCVR reduction of at least one category. This finding may not indicate an improvement in patient adherence, but it underscores two critical elements. First, knowing that patient self-reports are seldom accurate, physicians in our studies may have chosen to go by their own hic et nunc assessment - with clinical functionality to assess a potential problem quickly and without needing validation. Second, they may have adapted their clinical approach if they sensed manifest (or risk for) non-adherence behavior. Sensing may have been the clinical trigger, not whether their visual analog scale rating was congruent with actual patient behavior (most likely, it wasn't). It may have led them to implement some or all of the suggestions offered by Osterberg and Blaschke, ${ }^{68}$ but most likely clinical experience taught them to be helpful. Hypothetically, patient adherence may be the conjoint result of clinician alertness and sensitivity, integration of assessment and immediate intervention in the clinical encounter, and the sensitization and (partial) responsiveness of the patient.

\section{Class effects on treatment outcomes}

Clinicians do indeed exert a class effect over the patients they treat (and contribute to studies). We already discussed above the specific findings from our valsartan findings. The implications are broader. Clinicians need to be aware that how they assess, diagnose, and treat their patients has a class effect: a core similarity that transcends patients, may very well constitute the primary driver of their approach to hypertension management, and is tied to their education, training, exposure, 
and experience. More generally, any claims of individualized treatment tailored to each patient separately should be taken with some scepticism. Patterns of care are a reality - and not necessarily negatively so. Our studies only demonstrate a) that a significant amount in outcome variability is attributable to clinicians, and $b$ ) that some positive and negative drivers can be identified through modeling.

It is useful here to speculate about class effects beyond individual clinicians. Though typical for the Belgian primary care system, most physicians in our studies were in solo practice, and being part of a group or hospital-based practice may add another layer of class effect. For instance, we have found that hemoglobin outcomes in the management of anemia secondary to antineoplastic treatment are a function of center, country, and (European) region where the patient was treated. ${ }^{69}$

\section{Scientific issues}

\section{Replication}

RCTs tend to be replicated in ways that closely resemble the methodological and statistical platforms of the reference study - the goal being confirmation of initial (statistically powered) findings. Methodological and statistical similarity is seldom true in observational studies. In the case of valsartan, it explains the pervasive heterogeneity of studies and the quasi impossibility of synthesizing these studies in ways that consider differences in approach. The merit of our research program of seven valsartan-focused studies is that, despite some minor occasional differences between studies, these investigations were virtually identical in approach. Where differences in results were observed, these could be explained with appropriate certainty as a function of treatment regimen or sample. Findings that were consistent across studies can be assumed to be robust.

\section{Observational studies, treatment effects, and causality}

Our studies also underscore the importance of observational studies in determining the real-world effectiveness of treatment regimens. Poorly designed observational studies may under- or overestimate treatment effects. Yet there is strong empirical evidence that well-designed pharmacoepidemiologic observational studies provide not only accurate estimates of treatment effectiveness, but also broaden the understanding of the clinical dynamics of treatment, clinician, patient, and environment..$^{70,71}$

Many physicians continue to hold the (erroneous) belief that only RCTs permit inferences of causality - even when they would not challenge the Surgeon General's Report on the health effects of smoking ${ }^{72}$ (associative evidence) or would not advocate a randomized trial of adequate versus inadequate hemodialysis when the latter has clearly been linked to mortality ${ }^{73}$ (associative evidence rendering RCTs unethical). The social and behavioral sciences have developed methodologies and statistical approaches to analyse nonexperimental data to enable decisions from individual people all the way up to populations and societies. The relevance and appropriateness of these findings for clinical research has been demonstrated for a long time, ${ }^{74}$ yet resistance to these principles and methods remains - discouragingly and scientifically indefensibly so.

To what extent do our studies provide evidence that valsartan is the cause of reductions in BP and TCVR - in interaction with and as a function of the many determinants that have been identified? Mosteller ${ }^{75}$ identifies four criteria: 1) consistency or that the same effects are achieved regularly, and across people and time; 2) responsiveness, ie, evidence that variations in treatment precede variations in effects; 3) a mechanism that explains how the effect is created; and, citing Lipsey, ${ }^{76} 4$ ) uniqueness, or the ability to dismiss alternative explanation of the effect other than the treatment. Recently, Harrell argued that causal inferences from observational data can be trusted if 1 ) the prognostic factors are well understood and were collected; 2) the data are rich, accurate, and collected purposively; 3 ) treatment by indication is well understood/characterized; 4) the research is reproducible; 5) statistical analysis is appropriate; and based on 6) a prespecified analytic plan. ${ }^{77}$ The studies in our research program meet both the Mosteller and Harrell sets of criteria.

\section{TCVR as an effectiveness indicator}

The TCVR classification used in the BSCORE and EXCELLENT studies comprised five levels: average risk, low added risk, moderate added risk, high added risk, and very high added risk. Conceivably, the five levels might be too limited to sensitively and accurately quantify TCVR; as might be the nine levels of change in TCVR $(-4$ to +4$)$. The fact that in both studies, as well as a recent study on aliskiren, ${ }^{13}$ this method differentiated sufficiently among patients to be retained in modeling emphasizes the appropriateness and relevance of TCVR as an effectiveness indicator. As noted, future studies should incorporate other elements of TCVR.

\section{Conclusion}

This paper described a unique translational research program of seven studies on the real-world effectiveness of valsartan, 
among the most widely prescribed antihypertensive agents. In its different formulations, valsartan has major 'real-world' pharmacotherapeutic benefits in lowering BP and TCVR within a 90-day time period in patients in whom prior line treatment failed or was not tolerated. It is essential to understand the patient- and physician-related determinants of BP and TCVR outcomes associated with valsartan treatment. The evidence from our translational research program is robust: the findings are persistent across time, formulations, patients, and clinicians. Importantly, clinicians and patients need to be aware of the many treatment-, clinician-, and patient-related variables that may 'cause' variations in BP and TCVR outcomes. Many of these variables are modifiable and manageable through careful intervention and responsive patient self-care behavior.

\section{Acknowledgments}

The seven studies reviewed in this paper were sponsored by Novartis Pharma.

The authors thank Sandy Kramer and Jennifer Martin, Arizona Health Sciences Library, for their expert assistance with the literature search.

\section{Independence of Writing Committee}

The Writing Committee consisted of Ivo Abraham, Karen MacDonald, and Christopher Lee. All content decisions were made by the external authors. Sponsor had right of review and comment; co-authors affiliated with sponsor refrained from undue influence.

\section{Disclosure}

Stefaan Vancayzeele, Christine Hermans, Ann Aerts, and Heidi Brié are employees of Novartis Pharma. Ivo Abraham, Karen MacDonald, and Christopher Lee are employees of Matrix45. By company policy, employees are prohibited from owning equity in client organizations (except through mutual funds or other independently administered collective investment instruments) or contracting independently with client organizations. Matrix45 provides similar services to those described in this article to other biopharmaceutical companies on a non-exclusivity basis.

No services were provided by writers or editors employed by a medical education and communication company.

\section{References}

1. Saseen J, Carter B. Hypertension. In: DiPiro J, Talbert R, Yee G, Matzke G, Wells B, Posey L, editors. Pharmacotherapy: A Pathophysiologic Approach. 6th ed. New York: McGraw-Hill; 2005:187-217.

2. Black HR, Bailey J, Zappe D, Samuel R. Valsartan: more than a decade of experience. Drugs. 2009;69(17):2393-2414.
3. Bissessor N, White H. Valsartan in the treatment of heart failure or left ventricular dysfunction after myocardial infarction. Vasc Health Risk Manag. 2007;3(4):425-430.

4. Chrysant SG. Fixed combination therapy of hypertension: focus on valsartan/hydrochlorothiazide combination (Diovan/HCT). Expert Rev Cardiovasc Ther. 2003;1(3):335-343.

5. Chrysant SG, Chrysant GS. Clinical experience with angiotensin receptor blockers with particular reference to valsartan. J Clin Hypertens (Greenwich). 2004;6(8):445-451.

6. Fogari R, Zoppi A. A drug safety evaluation of valsartan. Expert Opin Drug Saf.

7. Abraham I. Conceptual and methodological issues in effectiveness research [In Japanese]. Kango Kenkyu - The Japanese Journal of Nursing Research. 2008;41(6):463-467.

8. Westfall JM, Mold J, Fagnan L. Practice-based research -"Blue Highways" on the NIH roadmap. JAMA. 2007;297(4):403-406.

9. Mancia G, De Backer G, Dominiczak A, et al. 2007 Guidelines for the Management of Arterial Hypertension: The Task Force for the Management of Arterial Hypertension of the European Society of Hypertension (ESH) and of the European Society of Cardiology (ESC). J Hypertens. 2007;25(6):1105-1187.

10. Mancia G, Laurent S, Agabiti-Rosei E, et al. Reappraisal of European guidelines on hypertension management: a European Society of Hypertension Task Force document. Blood Press. 2009;18(6):308-347.

11. Conroy RM, Pyorala K, Fitzgerald AP, et al. Estimation of ten-year risk of fatal cardiovascular disease in Europe: the SCORE project. Eur Heart J. 2003;24(11):987-1003.

12. Abraham I. Integrating blood pressure and $\mathrm{HbAl}$ c outcomes into TCVR as a treatment outcome (e-Letter). Ann Intern Med. December. http:// www.annals.org/content/152/11/689.full/reply\#annintmed_el_124829. Accessed December 7, 2010.

13. Verpooten GA, Aerts A, Coen N, et al. Antihypertensive effectiveness of aliskiren for the 'real-world' management of hypertension: multilevel modelling of 180-day blood pressure outcomes (the Belgian DRIVER Study). Int J Clin Pract. 2010;65(1):54-63.

14. Steinwachs D, Wu A, Cagney K. Outcomes research and quality of care. In: Spilker B, editor. Quality of Life and Pharmacoeconomics in Clinical Trials. 2nd ed. Philadelphia: Lippincott-Raven; 1996: $747-752$.

15. Abraham I, Reel L, Armstrong E. A definition of comparative effectiveness research (e-Letter). BMJ. http://www.bmj.com/content $/ 341 / \mathrm{bmj}$. c4662/reply\#bmj_el_241642. Accessed December 7, 2010.

16. Chobanian AV. The hypertension paradox - more uncontrolled disease despite improved therapy. $N$ Engl J Med. 2009;361(9): 878-887.

17. Chobanian AV, Bakris GL, Black HR, et al. The Seventh Report of the Joint National Committee on Prevention, Detection, Evaluation, and Treatment of High Blood Pressure: the JNC 7 report. JAMA. 2003;289(19):2560-2572.

18. Guidelines Committee. European Society of Hypertension-European Society of Cardiology guidelines for the management of arterial hypertension. J Hypertens. 2003;21(6):1011-1053.

19. Van der Niepen P, Woestenburg A, Brie H, et al. Effectiveness of valsartan for treatment of hypertension: patient profiling and hierarchical modeling of determinants and outcomes (the PREVIEW study). Ann Pharmacother. 2009;43(5):849-861.

20. Berlowitz DR, Ash AS, Hickey EC, et al. Inadequate management of blood pressure in a hypertensive population. $N$ Engl $J$ Med. 1998;339(27):1957-1963.

21. Fagard RH, Van Den Enden M, Leeman M, Warling X. Survey on treatment of hypertension and implementation of World Health Organization/ International Society of Hypertension risk stratification in primary care in Belgium. J Hypertens. 2002;20(7):1297-1302.

22. Van der Niepen P, Giot C, van de Borne P. Prevalence of isolated uncontrolled systolic blood pressure among treated hypertensive patients in primary care in Belgium: results of the I-inSYST survey. J Hypertens. 2008;26(10):2057-2063. 
23. Ong KL, Cheung BM, Man YB, Lau CP, Lam KS. Prevalence, awareness, treatment, and control of hypertension among United States adults 1999-2004. Hypertension. 2007;49(1):69-75.

24. Staessen JA, Wang JG, Thijs L. Cardiovascular prevention and blood pressure reduction: a quantitative overview updated until 1 March 2003. J Hypertens. 2003;21(6):1055-1076.

25. Kannel WB. Elevated systolic blood pressure as a cardiovascular risk factor. Am J Cardiol. 2000;85(2):251-255.

26. Hajjar I, Kotchen TA. Trends in prevalence, awareness, treatment, and control of hypertension in the United States, 1988-2000. JAMA. 2003;290(2):199-206

27. Chapman RH, Benner JS, Petrilla AA, et al. Predictors of adherence with antihypertensive and lipid-lowering therapy. Arch Intern Med. 2005;165(10):1147-1152.

28. Hyman DJ, Pavlik VN. Self-reported hypertension treatment practices among primary care physicians: blood pressure thresholds, drug choices, and the role of guidelines and evidence-based medicine. Arch Intern Med. 2000;160(15):2281-2286.

29. Sisson SD, Rastegar D, Rice TN, Prokopowicz G, Hughes MT. Physician familiarity with diagnosis and management of hypertension according to JNC 7 guidelines. J Clin Hypertens (Greenwich). 2006;8(5):344-350.

30. Choudhry NK, Fletcher RH, Soumerai SB. Systematic review: the relationship between clinical experience and quality of health care. Ann Intern Med. 2005;142(4):260-273.

31. Birtwhistle RV, Godwin MS, Delva MD, et al. Randomised equivalence trial comparing three month and six month follow up of patients with hypertension by family practitioners. BMJ. 2004;328(7433):204

32. Johnson ML, Pietz K, Battleman DS, Beyth RJ. Therapeutic goal attainment in patients with hypertension and dyslipidemia. Med Care. 2006;44(1):39-46.

33. Abraham I, Lee C, MacDonald K. Patient adherence in pre- and postregistration studies: different objectives, different approaches. Invited Lecture at the 14th European Symposium on Patient Adherence, Compliance and Persistence, Łodz, Poland. http:/www.espacomp.eu/ pdf/Abraham\%20.pdf. Accessed December 22, 2010.

34. D’Agostino RB Sr, Grundy S, Sullivan LM, Wilson P. Validation of the Framingham coronary heart disease prediction scores: results of a multiple ethnic groups investigation. JAMA. 2001;286(2): $180-187$.

35. Abraham I, Lee C, Song M, et al. "Later, lazier, and unluckier": a heuristic profile of high vulnerability is an independent predictor of uncontrolled blood pressure (the PREVIEW study). Int J Gen Med. 2010;3:163-166.

36. Van der Niepen P, Brié H, Vancayzeele S, et al. Effectiveness of valsartan for the treatment of hypertension: hierarchical linear and logistic modeling of determinants and outcomes (the Belgian IMPROVE study). Poster presented at the 2009 meeting of the Belgian Association of Pharmaceutical Physicians, Brussels. 2009.

37. Novartis. ADVANCE Data on file.

38. Lins R, Brié H, Vancayzeele S, et al. Effectiveness of valsartan 160/ HCTZ25 for treatment of hypertension in difficult-to-treat or treatmentresistant patients: hierarchical linear and logistic modeling of determinants and outcomes (the Belgian INSIST study). Poster presented at the 2009 meeting of the Belgian Association of Pharmaceutical Physicians, Brussels. 2009.

39. Novartis. eNOVA data on file.

40. Lins R, Coen N, Aerts A, et al. Modeling of blood pressure and total cardiovascular risk outcomes after second-line valsartan therapy: the BSCORE study. Arch Cardiovasc Dis. In Press.

41. Lins R, Aerts A, Coen N, et al. Effectiveness of amlodipine-valsartan single-pill combinations: hierarchical modeling of blood pressure and total cardiovascular risk outcomes (the EXCELLENT Study). Ann Pharmacother. In Press.

42. Basile JN, Chrysant S. The importance of early antihypertensive efficacy: the role of angiotensin II receptor blocker therapy. J Hum Hypertens. 2006;20(3):169-175.
43. Kreft IGG, De Leeuw J. Introduction to Multilevel Modeling. Thousand Oaks, CA: Sage; 2002.

44. Verbeke G, Molenberghs G. Linear Mixed Models for Longitudinal Data. New York, NY: Springer-Verlag; 2000.

45. Kleinbaum DG, Klein M. Losistic Regression. 2nd ed. New York, NY: Springer-Verlag; 2005.

46. Law MR, Wald Mj, Morris JK, Jordan RE. Value of low dose combination treatment with blood pressure lowering drugs: analysis of 354 randomized trials. BMJ. 2003:326(7404):1427-1434.

47. Bramlage P, Bohm M, Volpe M, et al. A global perspective on blood pressure treatment and control in a referred cohort of hypertensive patients. J Clin Hypertens (Greenwich). 2010;12(9):666-677.

48. Egan BM, Zhao Y, Axon RN. US trends in prevalence, awareness, treatment, and control of hypertension, 1988-2008. JAMA. 2010;303(20): 2043-2050.

49. Wilkins K, Campbell NR, Joffres MR, et al. Blood pressure in Canadian adults. Health Rep. 2010;21(1):37-46.

50. Grassi G, Cifkova R, Laurent S, et al. Blood pressure control and cardiovascular risk profile in hypertensive patients from central and eastern European countries: results of the BP-CARE study. Eur Heart J. 2010;32(2):218-225.

51. Falaschetti E, Chaudhury M, Mindell J, Poulter N. Continued improvement in hypertension management in England: results from the Health Survey for England 2006. Hypertension. 2009;53(3):480-486

52. Leenen FH, Schiffrin EL. Control rates of hypertension in North America. Hypertension. 2010;56(4):571-572.

53. Sheridan SL, Viera AJ, Krantz MJ, et al. The effect of giving global coronary risk information to adults: a systematic review. Arch Intern Med. 2010;170(3):230-239.

54. Ahmad T, Mora S. Providing patients with global cardiovascular risk information: is knowledge power? Arch Intern Med. 2010;170(3): 227-228.

55. Agarwal R, Bills JE, Hecht TJ, Light RP. Role of home blood pressure monitoring in overcoming therapeutic inertia and improving hypertension control: a systematic review and meta-analysis. Hypertension. 2011;57(1):29-38.

56. Gasse C, Hense HW, Stieber J, Doring A, Liese AD, Keil U. Assessing hypertension management in the community: trends of prevalence, detection, treatment, and control of hypertension in the MONICA Project, Augsburg 1984-1995. J Hum Hypertens. 2001;15(1): 27-36.

57. Primatesta P, Poulter NR. Hypertension management and control among English adults aged 65 years and older in 2000 and 2001. J Hypertens. 2004;22(6):1093-1098.

58. Ostchega Y, Dillon CF, Hughes JP, Carroll M, Yoon S. Trends in hypertension prevalence, awareness, treatment, and control in older US adults: data from the National Health and Nutrition Examination Survey 1988 to 2004. J Am Geriatr Soc. 2007;55(7):1056-1065.

59. Lloyd-Jones DM, Evans JC, Levy D. Hypertension in adults across the age spectrum: current outcomes and control in the community. JAMA. 2005;294(4):466-472.

60. Abraham I, Demosthenes L, MacDonald K, et al. Hierarchical linear and logistic modeling of outcomes of antihypertensive treatment in elderly patients: findings from the PREVIEW study. Arch Gerontol Geriatr. 2010;51(1):45-53.

61. Bailey KR, Grossardt BR, Graves JW. Novel use of Kaplan-Meier methods to explain age and gender differences in hypertension control rates. Hypertension. 2008;51(4):841-847.

62. MacDonald K, Lee CS, Chen HC, et al. Gender-specific, multi-level determinants of outcomes of antihypertensive treatment: a sub-analysis of the Belgian PREVIEW study. J Hum Hypertens. 2011.

63. Eddy DM. Evidence-based medicine: a unified approach. Health Aff (Millwood). 2005;24(1):9-17.

64. Aapro M, Van Erps J, MacDonald K, et al. Managing cancer-related anaemia in congruence with the EORTC guidelines is an independent predictor of haemoglobin outcome: initial evidence from the RESPOND study. Eur J Cancer. 2009;45(1):8-11. 
65. Abraham I. Bringing the evidence-base to patient care: micro-evidence, micro-trialing, and e2-learning. Distinguished Lectureship, University of Arizona, 3 November 2006. Available at http://stream.nursing.ari zona.edu:8080/ramgen/presentation/IvoAbrahamEvidenceBase_3 No v2006.rm. Last accessed 24 December 2010.

66. Abraham I. Diagnostic discrepancy and clinical inference: a socialcognitive analysis. Genet Soc Gen Psychol Monogr. 1986;112:41-102.

67. DiMatteo MR, Giordani PJ, Lepper HS, Croghan TW. Patient adherence and medical treatment outcomes: a meta-analysis. Med Care. 2002; 40(9):794-811.

68. Osterberg L, Blaschke T. Adherence to medication. $N$ Engl J Med. 2005;353(5):487-497.

69. Aapro M, Ludwig H, Bokemeyer C, et al. Modeling of treatment response to erythropoiesis-stimulating agents as a function of centerand patient-related variables: results from the Anemia Cancer Treatment (ACT) study. Ann Oncol. 2009;20(10):1714-1721.

70. Benson K, Hartz AJ. A comparison of observational studies and randomized, controlled trials. $N$ Engl J Med. 2000;342(25):1878-1886.

71. Concato J, Shah N, Horwitz RI. Randomized, controlled trials, observational studies, and the hierarchy of research designs. $N$ Engl J Med. 2000;342(25):1887-1892.

72. US Department of Health and Human Services: The Health Consequences of Smoking: A Report of the Surgeon General. Atlanta, GA: US Department of Health and Human Services, Centers for Disease Control and Prevention, National Center for Chronic Disease Prevention and Health Promotion, Office on Smoking and Health; 2004.

73. Port FK, Pisoni RL, Bragg-Gresham JL, et al. DOPPS estimates of patient life years attributable to modifiable hemodialysis practices in the United States. Blood Purif. 2004;22(1):175-180.
74. Sechrest L, Perrin E, Bunker J. Research Methodology: Strengthening Causal Interpretations of Nonexperimental Data (Conference Proceedings, Tucson, AZ, 8-10 April 1987; PHS Report 90-3454). In: Department of Health and Human Services PHS, Agency for Health Care Policy and Research, ed. Vol Available on CD-ROM from the National Technical Information Service, Springfield, VA, PB90-101387. Rockville, MD.

75. Mosteller F. Improving research methodology. In: Sechrest L, Perrin E, Bunker J, editors. Research Methodology: Strengthening Causal Interpretations of Nonexperimental Data (Conference Proceedings, Tucson, AZ, 8-10 April 1987; PHS Report 90-3454). Department of Health and Human Services, Public Health Services, Agency for Health Care Policy and Research; 1990, pp. 221-230. Available on CD-ROM from the National Technical Information Service, Springfield, VA, PB90-101387; 1987:221-230.

76. Lispey M. Theory as method: small theories of treatments. In: Sechrest L, Perrin E, Bunker J, editors. Research Methodology: Strengthening Causal Interpretations of Nonexperimental Data (Conference Proceedings, Tucson, AZ, 8-10 April 1987; PHS Report 90-3454). Department of Health and Human Services, Public Health Services, Agency for Health Care Policy and Research; 1990, pp. 221-230. Available on CD-ROM from the National Technical Information Service, Springfield, VA, PB90-101387; 1987:33-52.

77. Harrell F. Confounding in observational studies. Paper presented at: the National Institutes of Health and the Agency for Healthcare Research and Quality conference on Methodological Challenges in Comparative Effectiveness Research; 2010 December 2-3;Bethesda, MD, USA.
Vascular Health and Risk Management

\section{Publish your work in this journal}

Vascular Health and Risk Management is an international, peerreviewed journal of therapeutics and risk management, focusing on concise rapid reporting of clinical studies on the processes involved in the maintenance of vascular health; the monitoring, prevention and treatment of vascular disease and its sequelae; and the involvement of

\section{Dovepress}

metabolic disorders, particularly diabetes. This journal is indexed on PubMed Central and MedLine. The manuscript management system is completely online and includes a very quick and fair peer-review system, which is all easy to use. Visit http://www.dovepress.com/ testimonials.php to read real quotes from published authors. 